\title{
Genomic signature of parity in the breast of premenopausal women
}

Julia Santucci-Pereira ${ }^{1 *+}\left(\mathbb{D}\right.$, Anne Zeleniuch-Jacquotte ${ }^{2,3 \dagger}$, Yelena Afanasyeva ${ }^{2+}$, Hua Zhong ${ }^{2 \dagger}$, Michael Slifker ${ }^{4}$, Suraj Peri ${ }^{4}$, Eric A. Ross ${ }^{4}$, Ricardo López de Cicco', Yubo Zhai' ${ }^{1}$ Theresa Nguyen ${ }^{1}$, Fathima Sheriff', Irma H. Russo ${ }^{1}$, Yanrong Su', Alan A. Arslan², ${ }^{2,}$ Pal Bordas ${ }^{6,7}$, Per Lenner ${ }^{7}$, Janet Åhman ${ }^{6}$, Anna Stina Landström Eriksson ${ }^{6}$, Robert Johansson ${ }^{8}$, Göran Hallmans ${ }^{9}$, Paolo Toniolo ${ }^{5}$ and Jose Russo ${ }^{1}$

\begin{abstract}
Background: Full-term pregnancy (FTP) at an early age confers long-term protection against breast cancer. Previously, we reported that a FTP imprints a specific gene expression profile in the breast of postmenopausal women. Herein, we evaluated gene expression changes induced by parity in the breast of premenopausal women.

Methods: Gene expression profiling of normal breast tissue from 30 nulliparous (NP) and 79 parous (P) premenopausal volunteers was performed using Affymetrix microarrays. In addition to a discovery/validation analysis, we conducted an analysis of gene expression differences in P vs. NP women as a function of time since last FTP. Finally, a laser capture microdissection substudy was performed to compare the gene expression profile in the whole breast biopsy with that in the epithelial and stromal tissues.

Results: Discovery/validation analysis identified 43 differentially expressed genes in P vs. NP breast. Analysis of expression as a function of time since FTP revealed 286 differentially expressed genes (238 up- and 48 downregulated) comparing all P vs. all NP, and/or P women whose last FTP was less than 5 years before biopsy vs. all NP women. The upregulated genes showed three expression patterns: (1) transient: genes upregulated after FTP but whose expression levels returned to NP levels. These genes were mainly related to immune response, specifically activation of T cells. (2) Long-term changing: genes upregulated following FTP, whose expression levels decreased with increasing time since FTP but did not return to NP levels. These were related to immune response and development. (3) Long-term constant: genes that remained upregulated in parous compared to nulliparous breast, independently of time since FTP. These were mainly involved in development/cell differentiation processes, and also chromatin remodeling. Lastly, we found that the gene expression in whole tissue was a weighted average of the expression in epithelial and stromal tissues.

Conclusions: Genes transiently activated by FTP may have a role in protecting the mammary gland against neoplastically transformed cells through activation of T cells. Furthermore, chromatin remodeling and cell differentiation, represented by the genes that are maintained upregulated long after the FTP, may be responsible for the lasting preventive effect against breast cancer.
\end{abstract}

Keywords: Gene expression profiling, Pregnancy, Breast differentiation, Parous and nulliparous breast transcriptome, Immune response, Breast cancer risk, Normal breast transcriptome

\footnotetext{
* Correspondence: julia.pereira@fccc.edu

†ulia Santucci-Pereira, Anne Zeleniuch-Jacquotte, Yelena Afanasyeva and

Hua Zhong contributed equally to this work.

${ }^{1}$ The Irma H. Russo, MD Breast Cancer Research Laboratory, Fox Chase

Cancer Center - Temple University Health System, 333 Cottman Ave, P2051,

Philadelphia, PA 19111, USA

Full list of author information is available at the end of the article
}

(c) The Author(s). 2019 Open Access This article is distributed under the terms of the Creative Commons Attribution 4.0 International License (http://creativecommons.org/licenses/by/4.0/), which permits unrestricted use, distribution, and reproduction in any medium, provided you give appropriate credit to the original author(s) and the source, provide a link to the Creative Commons license, and indicate if changes were made. The Creative Commons Public Domain Dedication waiver (http://creativecommons.org/publicdomain/zero/1.0/) applies to the data made available in this article, unless otherwise stated. 


\section{Background}

The association of parity with breast cancer risk is well documented by both epidemiological and experimental data [1-4]. While the relationship is complex, with a transient increase in risk after each full-term pregnancy (FTP), the long-term effect for women who have their first FTP at an early age is a marked reduction in risk [5]. A better understanding of the molecular mechanisms underlying the effects of parity on the breast may help develop strategies to prevent breast cancer.

We previously reported the results of a study that assessed gene expression differences in the breast of 67 parous (P) and 40 nulliparous (NP) postmenopausal women who were free of any pathology and had volunteered to undergo a tissue biopsy [6-8]. We reported that in the postmenopausal breast, parity-induced gene expression changes were related to differentiation of this organ [6]. More specifically, we found that genes upregulated in the P breast, as compared to the NP breast, represented biological processes involved in differentiation and development, cell junction, RNA metabolic processes, and splicing machinery. The downregulated genes represented biological processes involved in cell proliferation, regulation of IGF-like growth factor receptor signaling, somatic stem cell maintenance, muscle cell differentiation, and apoptosis [6,7].

We here report on a study with a similar design and conducted in the same general population, but focusing on premenopausal women. The main objective of this study was to assess the parity-associated gene expression differences in the breast of premenopausal women. Because the breast undergoes involution after pregnancy and there is a short-term increase in breast cancer risk following each FTP, we examined the gene expression differences in P vs. NP women as a function of time since last FTP. Additionally, we conducted a substudy, in which laser capture microdissection (LCM) was used to isolate breast epithelial cells from the stroma to evaluate how the gene expression observed in RNA extracted from whole breast tissue relates to gene expression in RNA extracted from breast epithelial cells and from stroma separately.

\section{Methods}

\section{Study population and eligibility criteria}

Study subjects were volunteers recruited among healthy women between the ages of 29 and 47 years and residing in Norrbotten County, Sweden. Exclusion criteria included a history of any cancer, complete bilateral oophorectomy, breast biopsy or breast implants, and hormonal treatment for infertility. Women who had completed a FTP or breastfed in the 12 months prior to enrollment, used oral contraceptives in the 6 months prior to enrollment, or used thyroid or steroid hormones, anti-coagulants, or diabetes medications in the 3 months prior to enrollment were also ineligible. The study was approved by the Regional Ethical Review Board for Northern Sweden at the University of Umeå, Sweden.

Volunteers who signed informed consent were scheduled for a biopsy. Women who had not had a mammogram within the year preceding enrollment received one prior to the biopsy to exclude breast cancer. Parous (P) women were defined as women who had had one or more full-term pregnancies, defined as a pregnancy lasting at least 37 weeks. The nulliparous (NP) group included women who had never been pregnant or who had no history of pregnancies lasting more than 8 weeks.

\section{Data and breast tissue collection}

Eligible volunteers completed a questionnaire that collected data on reproductive history, medical history, height and weight, first-degree family history of breast cancer, history of tobacco use, and current medications. Breast core needle biopsies were performed by two experienced radiologists (P. Bordas and A. Eriksson) at the Mammography Department at Sunderby Hospital, Luleå, Sweden. A 12 -Gauge BARD ${ }^{\circ}$ MONOPTY $^{\circ}$ core biopsy needle was used, and four to eight biopsies were taken from the upper outer quadrant of one breast. One biopsy specimen was placed in 70\% ethanol for histopathological analysis, and the remaining in RNALater (Ambion) solution. Tissue samples were stripped of all personal identifiers and sent to Fox Chase Cancer Center for analysis. All samples were first reviewed by the study pathologist (J. Russo) to confirm the absence of atypia or cancer. During all the experiments, the researchers at Fox Chase Cancer Center were blinded to the parity status of the samples.

\section{Gene expression microarrays}

Total RNA from the biopsies was isolated using the Allprep RNA/DNA Mini Kit (Qiagen, Alameda, CA, USA). Quantity and quality of total RNA were assessed using NanoDrop v3.3.0 (NanoDrop Technologies, Wilmington, DE, USA) and Agilent 2100 Bioanalyzer (Agilent Technologies, CA, USA), respectively.

GeneChip Expression 3'-Amplification Two-Cycle cDNA Synthesis Kit (Affymetrix, Santa Clara, CA) was used for sample preparation and hybridization to Affymetrix Human Genome Gene Chip U133 Plus 2.0 arrays. For quality control purposes, we included in each batch ( 9 to 12 samples) one blinded duplicate sample from another batch.

After scanning, all microarrays were subjected to quality control $(\mathrm{QC})$ analysis to ensure that they were in the acceptable ranges for standard Affymetrix quality measures (Scale Factor, Percent Present, and Average Background). In addition, quality was assessed using graphical tools 
based on Affymetrix probe-level models (PLM) [9]. The Normalized Unscaled Standard Error (NUSE) plot, in particular, was used to disqualify lower quality arrays. Ten arrays $(8 \%-9 \mathrm{P}$ and $1 \mathrm{NP})$ did not fulfill quality criteria and were not included in the statistical analysis. The concordance correlation coefficients for the QC replicates were greater than $98 \%$.

\section{Data preprocessing and batch adjustment}

The Affymetrix data were analyzed using $R$ language for statistical computing ( $R$ version 2.14.1) [10] and Bioconductor [11]. Preprocessing methods and filtering criteria were similar to those used in our previous study $[6,7]$. Probesets for which both the proportion of present calls was $<75 \%$ and the difference in proportion of present calls between P and NP samples was $<25 \%$ were filtered out. Probesets with coefficient of variation (CV) across samples falling in the first quartile were also excluded. After filtering, 14,920 probesets (27\%) remained in the analysis. To account for inter-batch variability, the data were adjusted for batch using the ComBat method [12] implemented in the Bioconductor package sva [13].

\section{Statistical analysis of gene expression differences between parous and nulliparous women}

Linear regression models were used to identify probesets differentially expressed in P vs. NP samples. For each probeset, an unadjusted $p$ value measuring the significance of parity (yes/no) as an independent predictor of the log-transformed normalized gene expression value was calculated using single regression. We also used multiple regression analysis to identify differentially expressed probesets while controlling for potential confounders. The associations of subject characteristics with parity status and with gene expression were examined to identify potential confounders. Multivariate models were adjusted for age, body mass index (BMI) (which was associated with gene expression), and smoking duration (which was associated with both gene expression and parity status). We also adjusted for phase of cycle/use of a hormonal IUD, which could affect gene expression. False discovery rate (FDR) was used to control for multiple comparisons, using QVALUE in the R package version 1.28 .0 [14].

In order to identify the most robust parity-associated differences in gene expression, we first analyzed the data using a discovery/validation resampling approach. A discovery dataset was generated by selecting at random $2 / 3$ of the $\mathrm{P}$ women and $2 / 3$ of the NP women from the complete dataset. The remaining women formed a corresponding validation dataset. This step was repeated 12 times, leading to 12 discovery/validation dataset pairs. Probesets with FDR $<20 \%$ in any discovery dataset and $p$ value $<0.05$ in the corresponding validation dataset were considered validated for this dataset pair. We report the probesets (and corresponding genes) that were validated in at least 2 of the 12 dataset pairs.

The breast undergoes involution after pregnancy, which is likely to be associated with transient changes in gene expression. Further, although the long-term effect of early parity (before 35 years of age) is a reduction in breast cancer risk for pregnancy [5], it is well documented that there is a short-term increase in risk after each FTP. This suggests that the gene expression pattern in the breast may be different in the first few years after pregnancy than in later years. Therefore, we examined the parity-associated gene expression differences according to time between last FTP and biopsy (time since last pregnancy, TSLP). To optimize our chances of detecting TSLP-related differences in gene expression, we included in these analyses probesets that were differentially expressed (FDR $<10 \%$ and at least 1.2 -fold change) in the subgroup of $\mathrm{P}$ women whose last FTP was $\leq 5$ years before biopsy as compared to NP women, in addition to the probesets identified in the overall P-NP comparison. All women were included in these analyses and the patterns of expression were examined using clustering analysis in women classified according to TSLP $(<5,5-10$, or $>10$ years). Considering upregulated and downregulated genes separately, K-means cluster analyses were performed using Multiexperiment Viewer software (MeV-v.4.8.1) [15], with Pearson uncentered as distance metric. We examined the clusters formed after randomly setting the number of clusters (K) to $2,3,4$, or 5 .

\section{Mining for functional categories and pathways}

Data mining methods were applied to the differentially expressed genes to detect biological processes and pathways affected by parity. Ingenuity Pathways Analysis (IPA) software version 24390178 (QIAGEN) was used to investigate canonical pathways. Gene Ontology (GO) enrichment analysis was performed using conditional hypergeometric tests in the Bioconductor GOstats package [16]. We carried out analyses separately for each cluster of upregulated genes. GO (gene ontology) terms with $p$ value $<0.01$ were considered enriched. To evaluate the GO terms enriched by each cluster of genes, the terms were grouped into broader terms (developmental process, immune response, or others) following the GO hierarchical tree graph view from GO consortium [17]. Few genes were identified as downregulated; therefore, we did not conduct GO analyses for these genes but rather examined the literature to identify their roles.

In addition, genes that were validated by real-time RT-PCR were used for analysis into cBioPortal for Cancer Genomics (http://www.cbioportal.org/) [18, 19]. We evaluated whether these genes have been described to be modified in breast cancer cases available in the 
cBioPortal databank; in addition, an overall survival Kaplan-Meier curve was generated. In total, 11 genes were evaluated among 5796 breast cancer patients.

\section{Validation through real-time RT-PCR}

Eleven genes were selected for real-time RT-PCR analyses based on their biological roles in cell differentiation, proliferation, and chromatin remodeling. The assays were performed in the subset of $17 \mathrm{NP}$ and $20 \mathrm{P}$ samples (10 with TSLP $<5$, and 10 with TSLP $>5$ ) from whom sufficient RNA remained available, using $\mathrm{TaqMan}^{\circ}$ Gene Expression Master Mix and TaqMan ${ }^{\circ}$ Gene Expression Assays (Life Technologies). The end point used in the RT-PCR quantification, $\mathrm{Ct}$, was defined as the PCR cycle number at which each assay target passes the threshold. Each assay was normalized to $18 \mathrm{~S}$, a housekeeping gene used as endogenous control $(\Delta \mathrm{Ct})$. The difference between parous and nulliparous were estimated as the difference in mean $\Delta \mathrm{Ct}$ values $(-\Delta \Delta \mathrm{Ct})$. To assess the statistical significance of the differences between $\mathrm{P}$ and NP, batch-adjusted $p$ values were calculated using linear regression and comparisons with $p$ value $<0.10$ and fold change of at least 1.2 were considered statistically significant. Gene expression measured using RT-PCR and Affymetrix arrays were compared in the 37 subjects for whom both assays were used. Fold changes were estimated from multiple regressions using batch-adjusted, RMA (Robust Multi-Array Average)-normalized gene expression intensities, and intraclass and Spearman correlation coefficients were calculated.

\section{Immunohistochemical (IHC) staining}

Paraffin sections at $4 \mu \mathrm{m}$ were deparaffinized and placed in the antigen unmasking solution (Vector Laboratories, Burlingame, CA) and microwaved for $10 \mathrm{~min}$ at $100^{\circ} \mathrm{C}$. After cooling for $20 \mathrm{~min}$, slides were quenched with Peroxide Block (BioGenex, Fremont, CA; \#HK111) for $10 \mathrm{~min}$, followed by blocking with Power Block (BioGenex, \#HK085) for $20 \mathrm{~min}$ at room temperature. The sections were then stained with primary antibodies using a i6000 BioGenex Autostainer following standard protocol. The antibodies used were as follows: Cytokeratin 5 (BioGenex, \#AN484-10 M, pre-diluted), CD123 (BD Biosciences, \#554527; 1:400 dilution), LAMP3 (Abcam, \#ab111090), Desmocollin 3 (Abcam, \#ab190118; 1:150 dilution), CD2 (Abcam, \#ab131276; 1:200 dilution), and CD3D (Abcam, \#ab109531; 1:150 dilution). A Super Sensitive TM Polymer-HRP Detection System (BioGenex; \#QD430-XAKE) was used to detect the staining. The images were acquired at $\times 400$ magnification using an Aperio Digital Pathology Slide Scanner (Leica Biosystems, Buffalo Grove, IL) and analyzed by Aperio ImageScope Software (Leica Biosystems).

\section{Laser capture microdissection (LCM)}

In additional samples, we conducted a substudy to assess how gene expression in RNA extracted from whole breast tissue relates to gene expression in RNA extracted from epithelial and stromal tissues. Breast biopsy tissue fixed in RNA later was frozen and cryostat was used for histological sectioning. The frozen sections were then stained with hematoxylin and eosin specially prepared utilizing RNAse-free water to avoid RNA degradation [20]. LCM was performed using the VERITAS Microdissection Instrument (Arcturus, CA, USA) to select and capture all the epithelial tissue present in each section. The tissue left on the slide was then scrapped into a different tube and classified as stroma. The RNA extraction from the collected cells was performed using the Arcturus ${ }^{\oplus}$ PicoPure ${ }^{\circ}$ RNA Isolation Kit (Life Technologies). RNA was also extracted from a second core biopsy, in which no LCM was performed (called hereafter whole tissue, WT).

For each woman included in this substudy, three microarrays were performed in the same batch, using RNA extracted from (1) the epithelial cells of the mammary gland, (2) the stroma, and (3) WT. RNA amplification and labelling was performed using MessageAmpTM Premier RNA Amplification Kit (Life Technologies), and the arrays were hybridized to Affymetrix Human Genome Gene Chip U133 Plus 2.0 arrays. All arrays were subjected to $\mathrm{QC}$ analysis as described earlier. The arrays were RMA pre-processed, and probesets with $<75 \%$ of present calls and/or low CV (i.e., CV in the first quartile) were filtered out, resulting in 10,252 probesets for analysis. All values were log-transformed and normalized prior to analysis.

Nine subjects (5 NP and 4 P) had successful arrays for whole tissue, epithelial tissue, and stromal tissue. For each subject, a linear regression model was fitted across all genes. The gene expression values in the whole tissue were modeled as a linear function of the gene expression in epithelial and stromal tissues.

Gene expression comparison between the breast tissue types was performed for ten subjects $(5 \mathrm{P}$ and 5 NP) with successful epithelium and stroma arrays. For each probe, the fold changes were calculated as the median of within subject fold changes [expression in epithelium] / [expression in stroma] for each subject. A paired two-sample $t$-test was performed for each probe set, and $p$ values were adjusted for multiple comparisons using the FDR approach. Probes with FDR $<10 \%$ and fold changes of at least $20 \%$ were considered statistically different between epithelium and stroma. GO analysis was performed using the same methodology described above. The small number of samples limited our gene expression analyses between tissue types in function of parity. 


\section{Results}

\section{Volunteers included in the analysis}

A total of 307 women between ages 29 and 47 volunteered between March 2011 and June 2012 (Fig. 1). After exclusions related to eligibility, lack of epithelial structures, or QC failures, samples from 109 women (30 NP and $79 \mathrm{P}$ ) were included in the main study comparing $\mathrm{P}$ vs. NP, and samples from 10 women were included in the LCM substudy comparing the tissue types (Fig. 1).

$\mathrm{P}$ and NP women were similar with respect to most characteristics, such as age of menarche, breast density, and body mass index (BMI) (Table 1). However, the median age and median smoking duration were lower in NP than $\mathrm{P}$ women, and a larger proportion of $\mathrm{P}$ had a hormonal intra-uterine device (IUD).

\section{Differential gene expression}

Using the discovery and validation approach described in "Methods", 54 probesets, representing 43 genes (Table 2), were differentially expressed between $\mathrm{P}$ and NP women. Of the 43 genes, 40 were upregulated and 3 downregulated in the parous premenopausal breast (Table 2). Upregulated genes in the $\mathrm{P}$ breast included APOBEC3G, DSC3, FZD8, and EAF2, while FOXQ1 was among the downregulated genes.
Analyses of gene expression according to TSLP identified 286 genes (416 probesets) differentially expressed between $\mathrm{P}$ and NP samples (Fig. 2). Among these, 238 genes (352 probesets) were upregulated in $\mathrm{P}$ women, while 48 genes (64 probesets) were downregulated (Additional file 1).

For probesets upregulated in the $\mathrm{P}$ women, gene expression differences clustered in three expression patterns as a function of TSLP (Fig. 3). The first cluster consisted of 83 genes (107 probesets) which were upregulated following the last FTP, but whose expression progressively returned to the level of expression observed in NP women (Fig. 3a). These 83 genes were named "transient" genes. The second cluster consisted of probesets for which the P-NP differences were the highest for women with $<5$ years since last FTP, decreased with increasing TSLP but remained elevated as compared to NP women. The 95 genes (154 probesets) in this cluster were called "long-term changing" (Fig. 3b). In the last cluster, which included 60 genes (91 probesets), the fold changes between $\mathrm{P}$ an NP appeared constant, regardless of the TSLP. Therefore, we called these "long-term constant" genes (Fig. 3c).

Gene Ontology (GO) enrichment analyses showed an abundance of GO terms associated to developmental processes or immune response (Fig. 4), other less-abundant

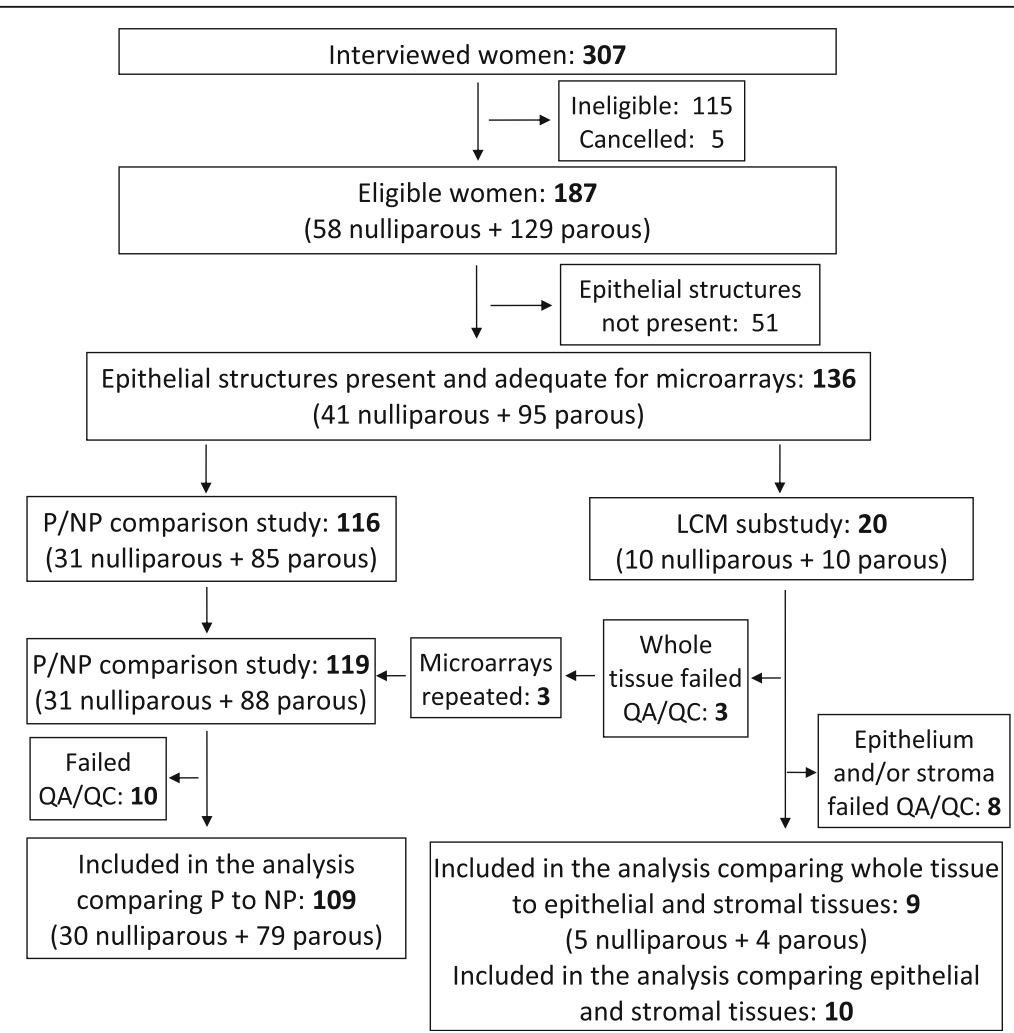

Fig. 1 Subject accrual and sample processing summary. Figure shows the number of women who volunteered, reasons for exclusion, and allocation of samples to the P/NP comparison study and LCM substudy 
Table 1 Descriptive characteristics of the study subjects

\begin{tabular}{|c|c|c|c|}
\hline Characteristics & Parous $(n=79)$ & $\begin{array}{l}\text { Nulliparous } \\
(n=30)\end{array}$ & $p$ value \\
\hline Age at visit, years & $\begin{array}{l}39.9 \\
(30.1,47.3)\end{array}$ & $\begin{array}{l}35.8 \\
(30.1,46.2)\end{array}$ & 0.03 \\
\hline \multicolumn{4}{|l|}{ Number of FTP } \\
\hline 1 & $13(16 \%)$ & & \\
\hline 2 & $44(46 \%)$ & & \\
\hline $3+$ & $22(28 \%)$ & & \\
\hline \multicolumn{4}{|l|}{ Time since last FTP, years } \\
\hline$\leq 5$ & $30(39 \%)$ & & \\
\hline $6-10$ & $29(37 \%)$ & & \\
\hline$>10$ & $20(25 \%)$ & & \\
\hline Age at first FTP, years & $26(18,27)$ & & \\
\hline Phase of cycle/hormonal IUD' & & & 0.05 \\
\hline Luteal & $21(28 \%)$ & $14(52 \%)$ & \\
\hline Ovulatory & $10(13 \%)$ & $4(15 \%)$ & \\
\hline Follicular & $21(28 \%)$ & $7(26 \%)$ & \\
\hline Hormonal IUD & $23(31 \%)$ & $2(7 \%)$ & \\
\hline Missing & 4 & 3 & \\
\hline OC ever use & $74(94 \%)$ & $27(90 \%)$ & 0.68 \\
\hline \multicolumn{4}{|l|}{ Breast density, BIRADS } \\
\hline 1 & $10(13 \%)$ & $4(13 \%)$ & 0.38 \\
\hline 2 & $16(20 \%)$ & $2(7 \%)$ & \\
\hline 3 & $10(13 \%)$ & $4(13 \%)$ & \\
\hline 4 & $43(54 \%)$ & $20(67 \%)$ & \\
\hline Age at menarche, years & $\begin{array}{l}13.0 \\
(11.0,16.0)\end{array}$ & $\begin{array}{l}13.0 \\
(11.0,15.0)\end{array}$ & 0.60 \\
\hline $\begin{array}{l}\text { Family history } \\
\text { of breast cancer }\end{array}$ & $7(9 \%)$ & $2(7 \%)$ & 0.99 \\
\hline Height, cm & $\begin{array}{l}165.0 \\
(148.0,184.0)\end{array}$ & $\begin{array}{l}166.5 \\
(157.0,174.0)\end{array}$ & 0.77 \\
\hline Weight, kg & $\begin{array}{l}68.0 \\
(41.0,115.0)\end{array}$ & $\begin{array}{l}64.0 \\
(46.0,97.0)\end{array}$ & 0.38 \\
\hline BMI & $\begin{array}{l}24.2 \\
(18.7,38.0)\end{array}$ & $\begin{array}{l}23.4 \\
(18.7,37.1)\end{array}$ & 0.24 \\
\hline \multicolumn{4}{|l|}{ Smoking } \\
\hline Never & $51(64 \%)$ & $20(67 \%)$ & 0.15 \\
\hline Past & $23(29 \%)$ & $5(17 \%)$ & \\
\hline Current & $5(6 \%)$ & $5(17 \%)$ & \\
\hline Smoking duration, years & $8.0(0.5,20.0)$ & $17.0(7.0,30.0)$ & 0.006 \\
\hline $\begin{array}{l}\text { Years since quitting } \\
\text { (past smokers) }\end{array}$ & $13.0(0.1,26.0)$ & $6.0(1.0,12.0)$ & 0.09 \\
\hline
\end{tabular}

${ }^{1} p$ value for IUD/ no IUD $=0.01$; excluding women having an IUD, there was no statistically significant difference in phase of menstrual cycle between P and NP

enriched GO terms were related to proliferation, intracellular transport, and cell death. Among the genes whose expression was transiently affected by parity $55 \%$, including CD8A, XCL1, and GZMA (Table 3), enriched GO terms related to immune response (Additional file 2).
Among the genes classified as long-term changing, 32\% were related to immune response (e.g., CD2) and 24\% were involved in developmental processes (e.g., EAF2) (Table 3, Additional file 3). Notably, of the long-term constant genes, $56 \%$ were related to developmental/differentiation processes (Additional file 4), including EGR3, DSC3, KRT5, and FZD8 (Table 3). These data indicate that the proportion of genes involved in immune response decreases among the genes that are upregulated irrespectively of TSLP, while the proportion of genes related to developmental processes increases (chi-squared $p$ value $=p<0.001$ ).

Evaluation of the canonical pathways represented by the differentially expressed genes also showed that pathways involved in signaling and activation of $\mathrm{T}$ cells were enriched by both transient and long-term genes (Fig. 5).

The 48 genes (64 probesets) downregulated in the $\mathrm{P}$ breast (Table 4) fell into two patterns. Twenty-two genes, including WIF1, EDN1, CXCL1, and FOXQ1, were downregulated in the $\mathrm{P}$ breast and remained with lower expression levels compared to NP breast irrespective of the number of years since last FTP. The remaining 26 genes were downregulated in women with TSLP $<5$ years; however, the expression increased reaching similar or higher levels than those in NP women when TSLP increased. These genes included DLG5, KDM4B, and TOX3. We did not conduct a GO enrichment analysis for these genes because of their limited number.

Finally, we examined genes reported to be related to chromatin remodeling. Among those upregulated, we observed APOBEC3G, TOX, UHRF1, and NAP1L2, while KDM4B and TOX3 were downregulated.

\section{Validation of microarray results}

$\mathrm{P} / \mathrm{NP}$ differences in gene expression were confirmed for eight out of the 11 genes analyzed by real-time PCR in a subset of 37 samples (20 P and $17 \mathrm{NP}$ ); Ct values, $\Delta \mathrm{Cts}$, and $-\Delta \Delta$ Cts are shown in Additional file 5. WIF1 was downregulated, while EAF2, BHLHE22, APOBEC3G, DSC3, KRT5, EGR3, and RASGRP1 were upregulated in the P breast (Table 5). The intraclass correlation coefficient (ICC) comparing the real-time to microarray measurements varied from 0.35 (EAF2) to 0.92 (WIF1), and Spearman correlation coefficients varied from 0.41 (EAF2) to 0.94 (WIF1) (Table 5).

We also analyzed the 11 selected genes in 5796 patients of breast cancer available in cBioPortal. One or more of these genes were altered in 770 (13\%) breast cancer patients. BHLHE22 was the gene that appears altered in the largest percentage of patients (6.9\%); the alterations included amplification, deep deletion, and missense mutations. The other ten genes showed to be altered in $1.5 \%$ or less patients (Table 6). An overall Kaplan-Meier survival curve has been generated comparing the group of patients 
Table 2 Genes differentially expressed between parous and nulliparous premenopausal women (discovery/validation approach)

\begin{tabular}{|c|c|c|c|c|c|}
\hline ProbelD & EntrezID & Symbol & GeneName & FDR & $\begin{array}{l}\text { Fold } \\
\text { change }\end{array}$ \\
\hline \multicolumn{6}{|c|}{ Genes upregulated in parous women } \\
\hline 206641_at & 608 & TNFRSF17 & Tumor necrosis factor receptor superfamily, member 17 & 0.013 & 2.41 \\
\hline 228504_at & 6332 & SCN7A & Sodium channel, voltage-gated, type VII, alpha subunit & 0.006 & 2.15 \\
\hline 237625_s_at & 3514 & IGKC & Immunoglobulin kappa constant & 0.006 & 1.94 \\
\hline 222838_at & 57823 & SLAMF7 & SLAM family member 7 & 0.017 & 1.93 \\
\hline 224342_x_at & 96610 & LOC96610 & BMS1 homolog, ribosome assembly protein (yeast) pseudogene & 0.032 & 1.80 \\
\hline 206121_at & 270 & AMPD1 & Adenosine monophosphate deaminase 1 & 0.021 & 1.76 \\
\hline 206033_s_at & 1825 & DSC3 & Desmocollin 3 & 0.006 & 1.68 \\
\hline 1555759_a_at & 6352 & CCL5 & Chemokine (C-C motif) ligand 5 & 0.018 & 1.67 \\
\hline 206478_at & 9834 & KIAA0125 & KIAA0125 & 0.006 & 1.65 \\
\hline 213193_x_at & 28639 & TRBC1 & T cell receptor beta constant 1 & 0.006 & 1.60 \\
\hline 207651_at & 29909 & GPR171 & G protein-coupled receptor 171 & 0.014 & 1.60 \\
\hline 206310_at & 6691 & SPINK2 & Serine peptidase inhibitor, Kazal type 2 (acrosin-trypsin inhibitor) & 0.006 & 1.59 \\
\hline 231647_s_at & 83416 & FCRL5 & Fc receptor-like 5 & 0.012 & 1.59 \\
\hline 203130_s_at & 3800 & $\mathrm{KIF} 5 \mathrm{C}$ & Kinesin family member $5 \mathrm{C}$ & 0.023 & 1.58 \\
\hline 205831_at & 914 & CD2 & CD2 molecule & 0.012 & 1.54 \\
\hline 216430_x_at & 28823 & IGLV1-44 & Immunoglobulin lambda variable 1-44 & 0.034 & 1.52 \\
\hline 211339_s_at & 3702 & ITK & IL2-inducible T cell kinase & 0.016 & 1.50 \\
\hline 206666_at & 3003 & GZMK & Granzyme K (granzyme 3; tryptase ॥) & 0.030 & 1.49 \\
\hline 204562_at & 3662 & IRF4 & Interferon regulatory factor 4 & 0.017 & 1.47 \\
\hline 213539_at & 915 & CD3D & CD3d molecule, delta (CD3-TCR complex) & 0.011 & 1.45 \\
\hline 206181_at & 6504 & SLAMF1 & Signaling lymphocytic activation molecule family member 1 & 0.014 & 1.45 \\
\hline 206150_at & 939 & CD27 & CD27 molecule & 0.019 & 1.44 \\
\hline 206991_s_at & 1234 & CCR5 & Chemokine (C-C motif) receptor 5 (gene/pseudogene) & 0.010 & 1.41 \\
\hline 235153_at & 138065 & RNF183 & Ring finger protein 183 & 0.026 & 1.41 \\
\hline 214470_at & 3820 & KLRB1 & Killer cell lectin-like receptor subfamily $B$, member 1 & 0.038 & 1.40 \\
\hline 230011_at & 150365 & MEI1 & Meiosis inhibitor 1 & 0.010 & 1.39 \\
\hline 211902_x_at & 10730 & YME1L1 & YME1-like 1 (S. cerevisiae) & 0.015 & 1.37 \\
\hline 221584_s_at & 3778 & KCNMA1 & Potassium large conductance calcium-activated channel, subfamily M, alpha member 1 & 0.034 & 1.36 \\
\hline 219551_at & 55840 & EAF2 & ELL associated factor 2 & 0.015 & 1.35 \\
\hline 220402_at & 63970 & TP53AIP1 & Tumor protein p53 regulated apoptosis inducing protein 1 & 0.015 & 1.35 \\
\hline 206761_at & 10225 & CD96 & CD96 molecule & 0.036 & 1.33 \\
\hline 212314_at & 23231 & SEL1L3 & Sel-1 suppressor of lin-12-like 3 (C. elegans) & 0.014 & 1.31 \\
\hline 204682_at & 4053 & LTBP2 & Latent transforming growth factor beta binding protein 2 & 0.006 & 1.31 \\
\hline 207655_s_at & 29760 & BLNK & B cell linker & 0.015 & 1.31 \\
\hline 204205_at & 60489 & APOBEC3G & Apolipoprotein B mRNA-editing enzyme, catalytic polypeptide-like 3G & 0.014 & 1.26 \\
\hline 223322_at & 83593 & RASSF5 & Ras association (RalGDS/AF-6) domain family member 5 & 0.024 & 1.25 \\
\hline 227405_s_at & 8325 & FZD8 & Frizzled family receptor 8 & 0.024 & 1.24 \\
\hline 211469_s_at & 10663 & CXCR6 & Chemokine (C-X-C motif) receptor 6 & 0.019 & 1.22 \\
\hline 233555_s_at & 55959 & SULF2 & Sulfatase 2 & 0.032 & 1.20 \\
\hline 209574_s_at & 753 & LDLRAD4 & Low-density lipoprotein receptor class A domain containing 4 & 0.045 & 1.15 \\
\hline \multicolumn{6}{|c|}{ Genes downregulated in parous women } \\
\hline 227475_at & 94234 & FOXQ1 & Forkhead box Q1 & 0.026 & 0.64 \\
\hline 244680_at & 2743 & GLRB & Glycine receptor, beta & 0.046 & 0.79 \\
\hline 236399_at & 54103 & PION & Pigeon homolog (Drosophila) & 0.041 & 0.86 \\
\hline
\end{tabular}




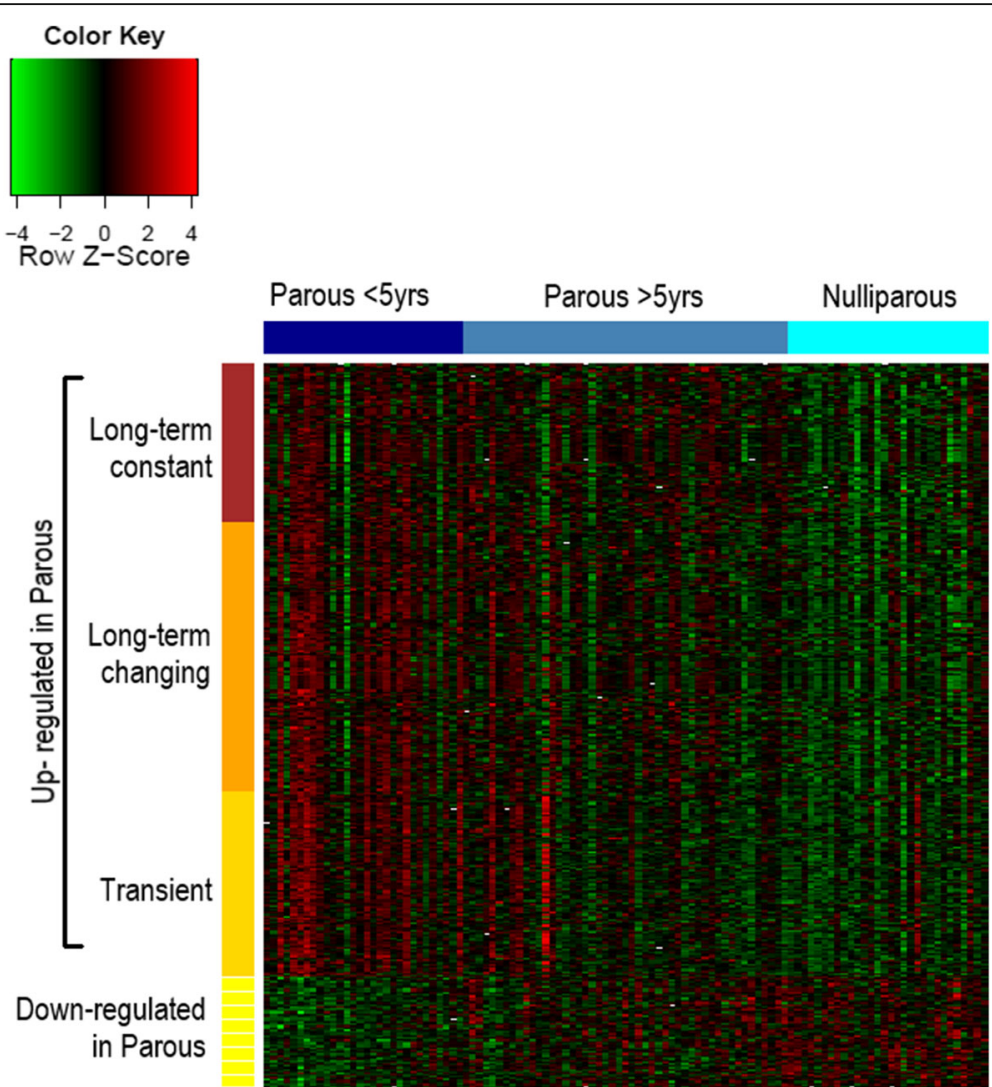

Fig. 2 Heatmap of all 416 probesets found differentially expressed between parous and nulliparous. Each column represents a volunteer. Dark blue represents parous women within 5 years since last full-term pregnancy, blue represents parous women with more than 5 years since pregnancy, and cyan represents nulliparous women. Each line corresponds to a probeset, which accordingly with its pattern of expression within the parous breast samples compared to nulliparous, was classified as downregulated (light yellow), transiently upregulated (yellow), long-term changing (orange), and long-term constant upregulated (brown)

with these 11 genes altered versus patients without the alterations. The group of patients that contain alteration in these genes has shorter overall survival, median of 143.13 versus 168.3 months, logrank test $p$ value $=9.09 \mathrm{e}-5$ (Fig. 6).

We performed IHC analyses to evaluate whether the changes in gene expression reflected into the protein expression levels. We have evaluated two proteins related to differentiation Desmocollin 3 and Cytokeratin 5 . These two markers were presented in all tested samples, and although we have observed slight upregulation of their genes by microarray and RT-PCR, we did not detect protein differences between $\mathrm{P}$ and NP breast tissues. Related to immune response, we evaluated markers for dendritic cells because of their role in antigen presentation for T cell activation. Using two markers CD123 and LAMP3, we detected few positive cells with no differences between $\mathrm{P}$ and NP samples. We also evaluated $\mathrm{CD} 2$ and CD3D, markers of $\mathrm{T}$ cell activation (Fig. 7). The percentage of positive cells for CD2 was low in both groups, we observed slight increase in the percentage of CD2-positive cells in parous women (1.6 times; $\mathrm{P}$ median $=0.59 \%$, NP median $=0.31 \%$ ); however, it was not statistically significant ( $p$ value $=0.156$ ). The overall percentage of CD3D-positive cells was higher ranging from 0.6 to $9.4 \%$. We confirmed a statistically significant twofold increase in the percentage of CD3D-positive cells in the $\mathrm{P}$ breast $(\mathrm{P}$ median $=3.28 \%$, NP median $=1.62 \%$, $p$ value $=0.006)($ Fig. 7$)$. We also compared whether the percentage of positive cells between $\mathrm{P}$ women with TSLP $\leq 5$ and $>5$ differed. For both CD2 and CD3D, we see a slight larger number of positive cells in TSLP $\leq 5$, but were not statistically significant $(\mathrm{CD} 2 p$ value $=0.16$ and CD3D $p$ value $=0.09$ )

\section{Laser capture microdissection (LCM) results}

We found that a linear function of gene expression levels in RNA from epithelial tissue and RNA from stromal tissue predicted extremely well the level of expression in RNA extracted from the whole tissue $\left(0.91<R^{2}<0.95\right)$, i.e., the gene expression in whole tissue was a weighted average of the gene expression in epithelial tissue and in stromal tissue for all nine individuals included in this substudy (Table 7). This was observed regardless of the proportion of each tissue type found on the paraffin 


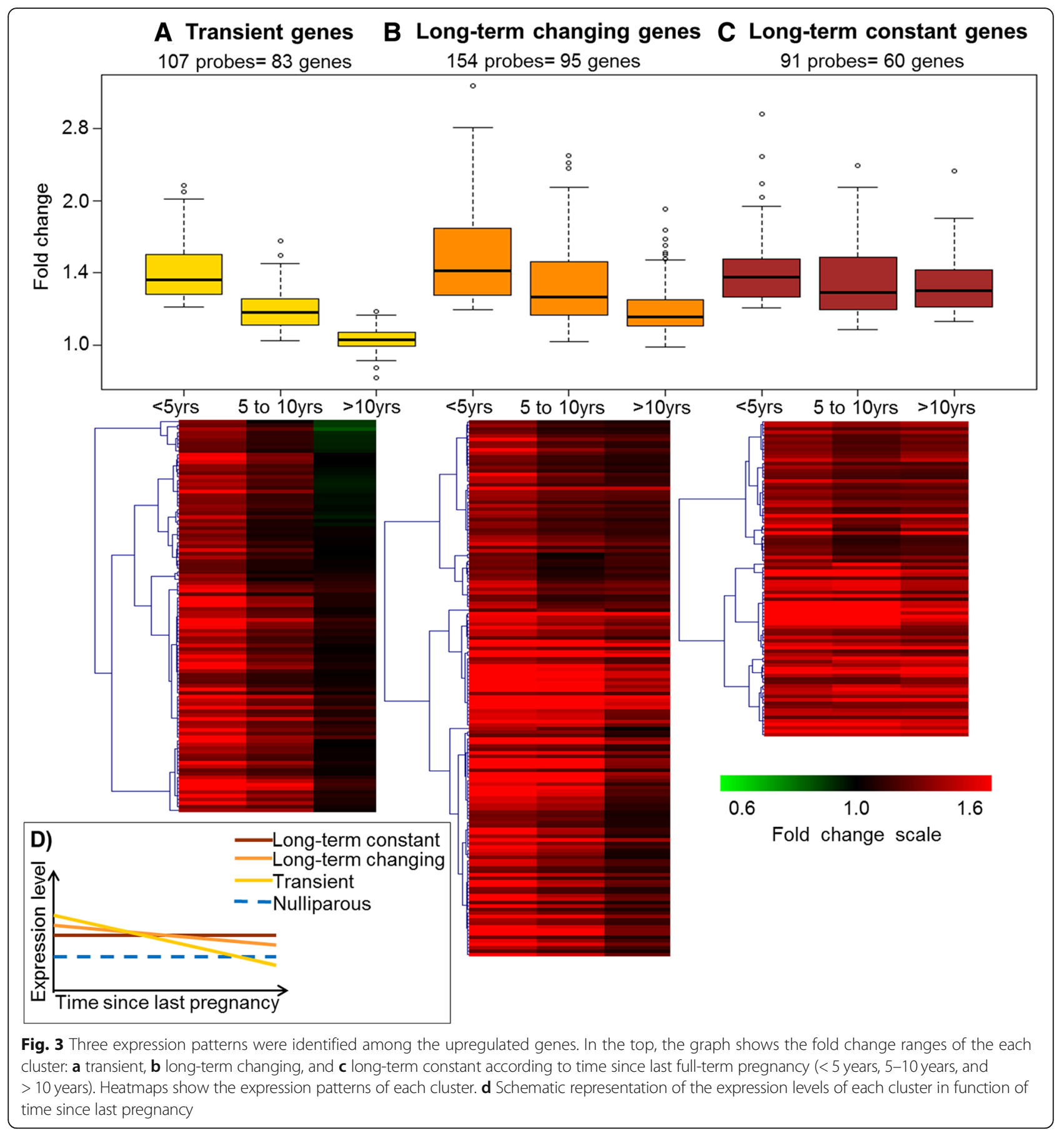

sections, which varied across individuals (regression coefficient for epithelial tissue ranged from 0.09 to 0.68 ).

Analysis of gene expression differences between epithelium and stroma showed 730 genes (956 probesets) with higher expression levels in the epithelium, while 663 genes (1020 probesets) were more expressed in the stroma (Additional file 6). GO analyses of these genes demonstrated a broader range of biological processes enriched by the genes with higher expression levels in the stroma (306 GO terms), which included cell motility, cell signaling, angiogenesis, development, and lipid process among other processes. Conversely, the genes with higher expression in the epithelium, enriched 12 GO terms, consisting a biological process involved in epithelial development and tight junction among other GOs (Additional file 7). 


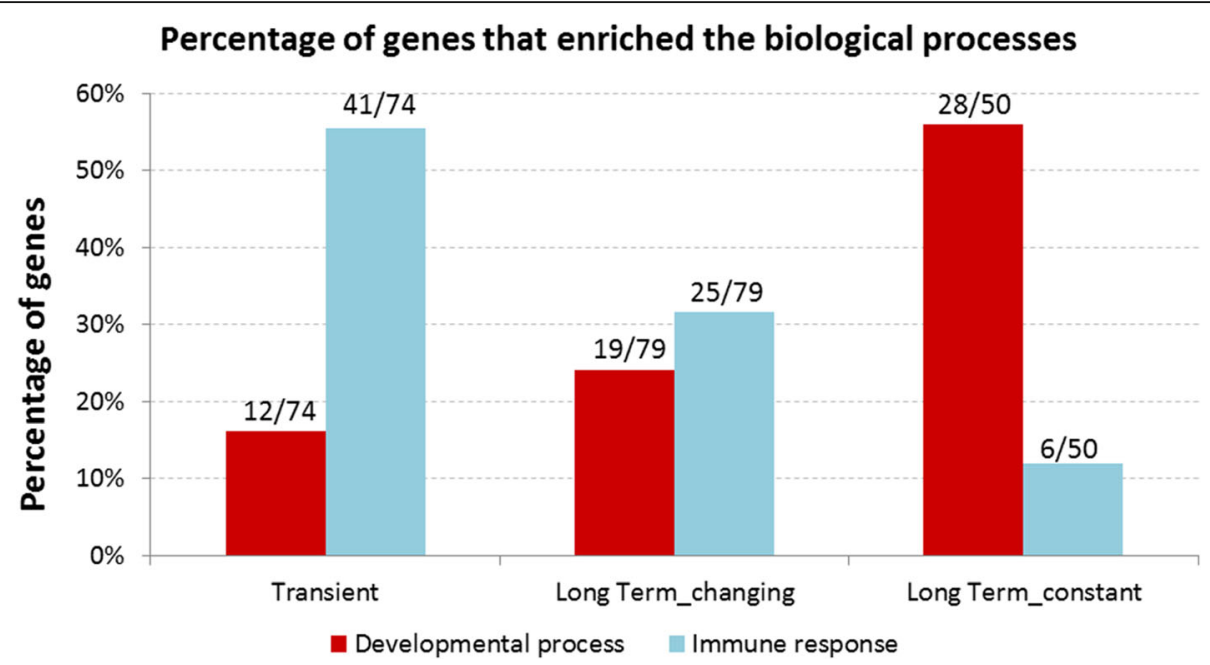

Fig. 4 Graph shows the percentage of genes associated with GO terms related to developmental processes (red) and immune response (blue) for each of the three clusters. 74, 79, and 50 are the total number of genes associated at least with one GO term for each cluster

\section{Discussion}

This study evaluated gene expression differences in parous and non-parous breast using biopsies from healthy premenopausal volunteers. Using a discovery/validation approach, we found 43 differentially expressed genes (Table 2). Evaluation of expression differences between NP and $P$ as a function of TSLP identified 238 genes upand 48 genes downregulated in the P breast. The downregulated genes fell into two patterns of expression (transient and long-term), while the upregulated genes fell into three patterns (transient, long-term changing, and long-term constant) (Fig. 3). Through GO enrichment analyses, we found that genes whose expression was transiently increased after pregnancy were mainly related to immune response. Long-term changing genes included immune- and development-related genes, while genes categorized as long-term constant were mainly involved in cell differentiation and developmental processes (Fig. 4). LCM performed in a small set of samples indicated that the gene expression observed on whole-tissue arrays corresponded to the weighted average of the gene expression observed in the epithelial and stromal tissues.

Among the 43 differentially expressed genes (Table 2) found in our discovery/validation analysis were DSC3 and KRT5, whose differential expression was confirmed by RT-PCR. These genes were also found in our previous study conducted in postmenopausal women $[6,7]$, indicating that the expression of these genes is durably modified by pregnancy. Consistent with this observation, DSC3 and KRT5 fell into the "long-term constant" category in our analysis by TSLP. These two genes are involved in cell communication and epithelial differentiation [21, 22]. Additionally, DSC3 has been suggested to act as a tumor suppressor [23-26], and its silencing is a common event in breast tumors [26].

While a discovery/validation approach is valuable to reduce the chance of false-positive results, our sample size was fairly small, which can lead to unstable results and lack of detection of some associations [27, 28]. This was a concern particularly because the breast undergoes major remodeling after a pregnancy/breastfeeding. Thus, genes may go through successive changes in pattern of expression after pregnancy, and analyses ignoring time since last pregnancy could miss transient expression modifications. We therefore also examined gene expression differences according to time since last pregnancy. To the best our knowledge, this is the first study that used a whole-transcriptome approach to demonstrate a cluster of biological functions following distinct expression patterns in the human breast following pregnancy.

The observation that the "long-term constant" genes were mainly involved in cell differentiation and developmental processes (Fig. 4) is consistent with the transcriptomic profile we previously described in the parous postmenopausal breast, in which upregulated genes showed enrichment of similar processes [6-8]. These findings indicate that the parity signature set after pregnancy remains until the postmenopausal years. Other development-related genes upregulated in the $\mathrm{P}$ breast and confirmed by RT-PCR were RASGRP1 (RAS guanyl-releasing protein 1-calcium and DAG-regulated), EGR3 (early growth response 3), and BHLHE22 (basic helix-loop-helix family member e22). These genes, in addition to differentiation, are known to regulate proliferation and cell growth [29-32].

Among the genes classified as developmental, we also found components of the WNT pathway. WNT 
Table 3 Genes that enriched developmental processes and immune response gene ontologies

\begin{tabular}{|c|c|c|c|c|c|}
\hline \multicolumn{6}{|l|}{ Transient genes } \\
\hline \multicolumn{6}{|c|}{ Developmental process } \\
\hline ANXA1 & CAMK4 & CD8A & CD27 & EOMES & ITK \\
\hline JAK3 & LCK & PTPN22 & PTPRC & SASH3 & THEMIS \\
\hline \multicolumn{6}{|c|}{ Immune response } \\
\hline ANXA1 & CAMK4 & CCL5 & CD8A & $C D 27$ & CD48 \\
\hline CD96 & CD247 & CORO1A & CST7 & CXCL14 & CXCL9 \\
\hline EOMES & FASLG & FYB & GZMA & HCST & IGLC1 \\
\hline IKZF1 & IL16 & IL7R & ITGAL & ITK & JAK3 \\
\hline KLHL6 & LAT & LAX1 & LCK & LCP2 & LY9 \\
\hline PRKCB & PTPN22 & PTPRC & SASH3 & SELPLG & SEMA4D \\
\hline sSH2D1A & SLAMF1 & THEMIS & TRAC & XCL1 & \\
\hline \multicolumn{6}{|c|}{ Long-term changing genes } \\
\hline \multicolumn{6}{|c|}{ Developmental process } \\
\hline C3 & CCR2 & CD2 & CXCL10 & DACT1 & DKK3 \\
\hline EAF2 & EPHA7 & FGF1 & FGFR2 & HCLS1 & HLA-DOA \\
\hline IL12RBI & IRF4 & LAMA2 & OSR2 & PDGFRA & SIPA1L1 \\
\hline \multicolumn{6}{|l|}{ SPHK1 } \\
\hline \multicolumn{6}{|c|}{ Immune response } \\
\hline APOBEC3G & BLNK & C1S & C3 & CCR2 & CD2 \\
\hline CD3D & CD38 & CRTAM & CXCL10 & GPR183 & HLA-DOA \\
\hline HLA-DPB1 & IGKC & $\mid L 12 R B 1$ & IRF4 & LPXN & MZB1 \\
\hline NFATC2 & PAWR & POU2AF1 & PRKCQ & SAMSN1 & SLAMF7 \\
\hline \multicolumn{6}{|l|}{ TRBC1 } \\
\hline \multicolumn{6}{|c|}{ Long-term constant genes } \\
\hline \multicolumn{6}{|c|}{ Developmental process } \\
\hline BHLHE22 & CCL19 & $C C L 2$ & DCN & DSC3 & EGR3 \\
\hline EPHB1 & FHL2 & FZD8 & GLI3 & GPR65 & KCNMA1 \\
\hline $\mathrm{KIF5C}$ & KRT5 & MYLK & NFASC & PRKCA & SALL1 \\
\hline SDC1 & SULF1 & SULF2 & TAGLN & TREM2 & TYMS \\
\hline VCAM1 & WIPF3 & $\mathrm{XDH}$ & $\mathrm{ZIC1}$ & & \\
\hline \multicolumn{6}{|c|}{ Immune response } \\
\hline CCL2 & CCL19 & GLI3 & HLA-DPA1 & HLA-DRA & VCAM1 \\
\hline
\end{tabular}

Italicized genes enriched both developmental and immune response processes

canonical and non-canonical pathways participate in cell fate determination, cell polarity, adhesion, and motility [33, 34], all important functions in the differentiation of the breast. Differentiation induced by parity has been demonstrated to alter WNT/Notch signaling in mice [35], and we have described alterations in the methylation profile of genes belonging to this pathway and its regulation in the postmenopausal breast [36]. In the current study, we observed two genes of this pathway upregulated in the P breast, FZD8 (frizzled family receptor 8) which is a transmembrane receptor transducing WNT signals, and EAF2 (ELL-associated factor 2), which is important for early embryonic development and critical for adult tissue homeostasis and prevention against tumor initiation [37, 38]. WNT inhibitory factor 1, WIF1, was downregulated in $\mathrm{P}$ women, and although methylation of WIF1 has been observed in several tumors [39], including breast cancer [40], this can be an indication that the WNT pathway has an important role in the shifting of the stem cells to a more differentiated status in the P breast, as demonstrated earlier $[8,41]$. Yet related to WNT pathway, we found FOXQ1 or forkhead box Q1, constantly downregulated in the P breast. This gene is a direct target of the canonical WNT pathway and its overexpression has been associated with different tumors and cancer cell lines [42]. Suppression of FOXQ1 inhibits cell proliferation, motility/invasion, and epithelial-mesenchymal transition phenotypes in cancer cells [43-45]; a similar effect could be predicted in the breast of $\mathrm{P}$ women.

Also consistent with our previous study in postmenopausal women, we observed several genes with roles in chromatin remodeling [8]. In the current study, there were four long-term upregulated genes involved in chromatin remodeling: APOBEC3G, TOX, UHRF1, and NAP1L2. These genes interact with chromatin, either by binding with histones or recruiting histone modifiers, influencing cell proliferation and differentiation among other biological processes [46-52]. In addition, APOBEC3G (apolipoprotein B mRNA-editing enzyme, catalytic polypeptide-like $3 G$ ) is involved in RNA editing [53], and deletion in APOBEC3 gene has been correlated to breast cancer risk [54]. The upregulation of these genes in the breast of $\mathrm{P}$ women years after delivery indicates chromatin remodeling is enabling a permanent differentiation of the breast epithelial cells.

We also evaluated whether selected genes from this study are modified in breast cancer cases. Of the genes evaluated, BHLHE22 was the most commonly modified in breast cancer $(6.9 \%$ of the cases). The other genes were altered in a small percentage of breast cancer cases (Table 6). Of interest is that patients who have some alteration (amplification, deep deletion, or missense mutation) in the tested genes have a lower overall survival (Fig. 6). Although this analysis can indicate that these genes are associated with breast cancer, our interpretation is limited because the parity status of these breast cancer cases is not available.

In addition to genes involved in development and chromatin remodeling, we observed a large number of genes known to participate in immune response. The immune system has several roles in the mammary gland, being important not only for protection against pathogens, but also it is secreted into the milk and participates at the different stages of the gland development, including involution [55-58]. Of great interest, most of these immune-related genes were only upregulated in the 


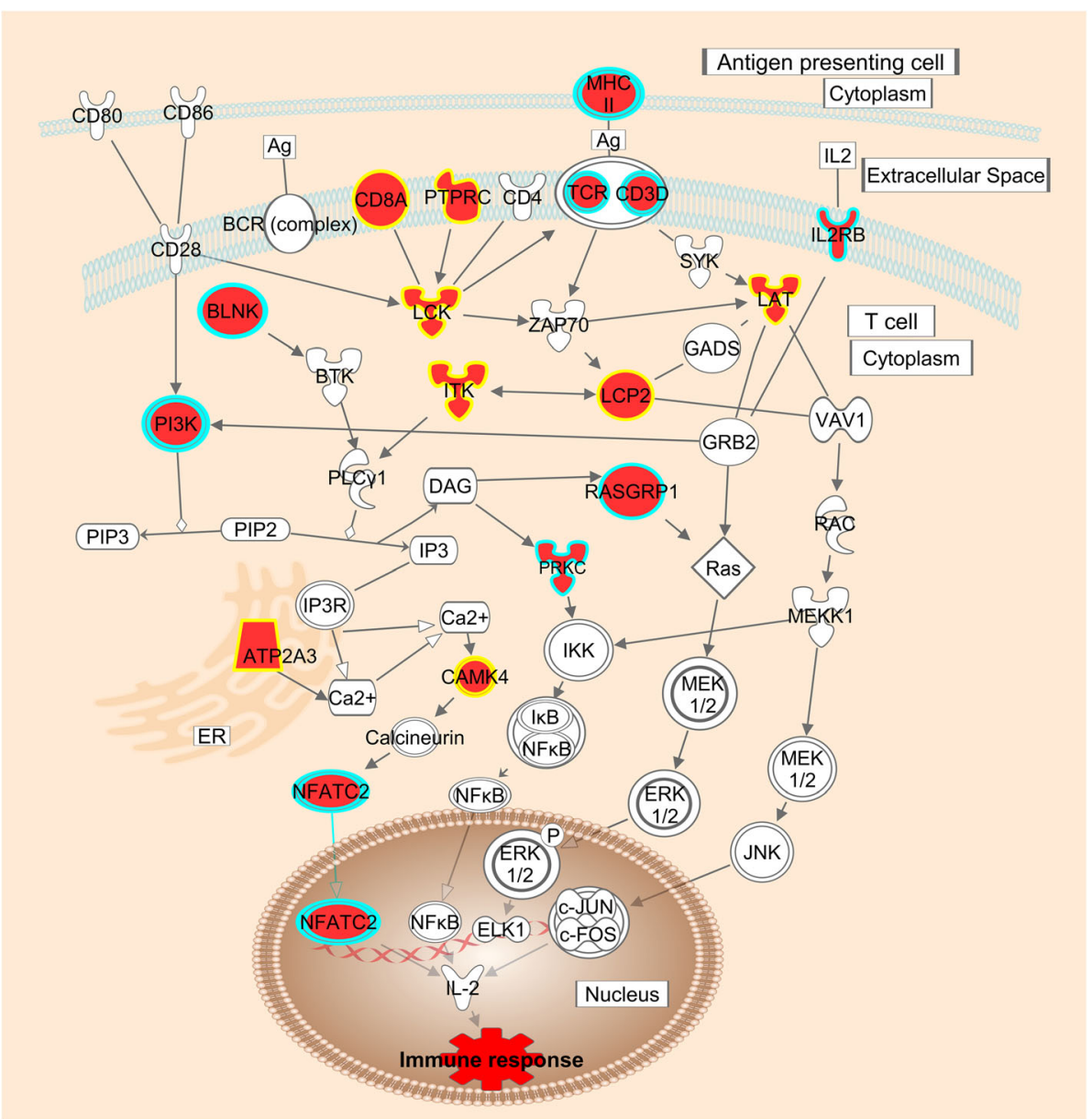

Fig. 5 Pathway representing T cell signaling. Genes in red were upregulated in the parous breast. Genes with a blue border had a long-term effect, while genes with a yellow border were transiently upregulated. Pathway was modified from IPA software (QIAGEN) using Path Designer

biopsies collected within 5 years since pregnancy. This observation is consistent with our previous work in postmenopausal women, in which we did not observe enrichment of immune response in an older population $[6,7]$. It is also in agreement with previous studies on molecular profiling of pregnancy performed in younger populations that reported changes in immune-response genes $[59,60]$.

Previous studies have showed differences in expression patterns of immune-related genes at distinct mammary developmental stages, before and/or after pregnancy in humans [59] and rodents [61, 62]. Rodent studies demonstrated that in the first days of mammary gland involution there is activation of genes related to acute-phase response and inflammation [61, 62], followed by activation of monocyte and lymphoid chemokines and immunoglobulin genes [61]. The inflammatory-like environment observed during the breast involution has been proposed as one of the mechanisms that could explain the transient increase in breast cancer risk observed after each pregnancy $[57,63]$. In this study, we observed that most of the genes that underwent transient changes in expression enriched biological processes related to activation and development of lymphocytes, mainly $\mathrm{T}$ cells (Additional file 2). Only one GO term related to inflammation (GO:0006925: inflammatory cell apoptotic process) was enriched among the transient genes (Additional file 2). This may be due to the fact that biopsies were collected at least 1 year after FTP and/or breastfeeding; thus, we may have missed an early inflammation stage. Both human and murine postpartum mammary glands have an organized influx of immune cells; however, these cells are not observed after 1 year postpartum in human, or 12 weeks in murine [57]. We have performed immunohistochemistry reactions for dendritic cells and T cell activation markers on a subset of our samples. Using antibodies anti-LAMP3 and anti-CD123 for dendritic cells, antigen presenters, we detected few positive cells and no differences between P and NP samples (data not shown). When using anti-CD2 and anti-CD3D, markers of $\mathrm{T}$ cell activation, we observed an increase in cells positive for CD3D in $\mathrm{P}$ 
Table 4 Genes downregulated within parous breast

\begin{tabular}{|c|c|c|c|}
\hline EntrezID & ProbelD & Symbol & GeneName \\
\hline \multicolumn{4}{|c|}{ Genes downregulated constantly } \\
\hline 653 & 205431_s_at & BMP5 & Bone morphogenetic protein 5 \\
\hline 694 & 1559975_at & BTG1 & B cell translocation gene 1, anti-proliferative \\
\hline 285382 & 242447_at & C3orf70 & Chromosome 3 open reading frame 70 \\
\hline 1277 & 202310_s_at & COL1A1 & Collagen, type I, alpha 1 \\
\hline 131873 & 242641_at & COL6A6 & Collagen, type VI, alpha 6 \\
\hline 2919 & 204470_at & CXCL1 & Chemokine (C-X-C motif) ligand 1 (melanoma growth-stimulating activity, alpha) \\
\hline 55184 & 219951_s_at & DZANK1 & Double zinc ribbon and ankyrin repeat domains 1 \\
\hline 1906 & 222802_at & EDN1 & Endothelin 1 \\
\hline 133121 & 229916_at & ENPP6 & Ectonucleotide pyrophosphatase/phosphodiesterase 6 \\
\hline 94234 & 227475_at & FOXQ1 & Forkhead box Q1 \\
\hline 2743 & 205280_at & GLRB & Glycine receptor, beta \\
\hline 253012 & 242601_at & HEPACAM2 & HEPACAM family member 2 \\
\hline 3736 & 230849_at & KCNA1 & Potassium voltage-gated channel, shaker-related subfamily, member 1 (episodic ataxia with myokymia) \\
\hline 79442 & 219949_at & LRRC2 & Leucine-rich repeat containing 2 \\
\hline 9848 & 205442_at & MFAP3L & Microfibrillar-associated protein 3-like \\
\hline 4300 & 204918_s_at & MLLT3 & Myeloid/lymphoid or mixed-lineage leukemia (trithorax homolog, Drosophila); translocated to, 3 \\
\hline 3340 & 1554010_at & NDST1 & N-Deacetylase/N-sulfotransferase (heparan glucosaminyl) 1 \\
\hline 11069 & 205651_x_at & RAPGEF4 & Rap guanine nucleotide exchange factor (GEF) 4 \\
\hline 950 & 201647_s_at & SCARB2 & Scavenger receptor class B, member 2 \\
\hline 1317 & 236217_at & SLC31A1 & Solute carrier family 31 (copper transporters), member 1 \\
\hline 116441 & 228489_at & TM4SF18 & Transmembrane $4 \mathrm{~L}$ six family member 18 \\
\hline 11197 & 204712_at & WIF1 & WNT inhibitory factor 1 \\
\hline \multicolumn{4}{|c|}{ Genes downregulated transiently } \\
\hline 170692 & 230040_at & ADAMTS18 & ADAM metallopeptidase with thrombospondin type 1 motif, 18 \\
\hline 267 & 202203_s_at & AMFR & Autocrine motility factor receptor, E3 ubiquitin protein ligase \\
\hline 56892 & 218541_s_at & C8orf4 & Chromosome 8 open reading frame 4 \\
\hline 401546 & 229964_at & C9orf152 & Chromosome 9 open reading frame 152 \\
\hline 760 & 209301_at & CA2 & Carbonic anhydrase II \\
\hline 54102 & 227742_at & CLIC6 & Chloride intracellular channel 6 \\
\hline 1281 & 211161_s_at & COL3A1 & Collagen, type III, alpha 1 \\
\hline 9231 & 229689_s_at & DLG5 & Discs, large homolog 5 (Drosophila) \\
\hline 54898 & 213712_at & ELOVL2 & ELOVL fatty acid elongase 2 \\
\hline 2069 & 205767_at & EREG & Epiregulin \\
\hline 2330 & 205776_at & FMO5 & Flavin containing monooxygenase 5 \\
\hline 2717 & 214430_at & GLA & Galactosidase, alpha \\
\hline 26585 & 218469_at & GREM1 & Gremlin 1, DAN family BMP antagonist \\
\hline 2892 & 230144_at & GRIA3 & Glutamate receptor, ionotropic, AMPA 3 \\
\hline 23704 & 222379_at & KCNE4 & Potassium voltage-gated channel, Isk-related family, member 4 \\
\hline 23030 & 212492_s_at & KDM4B & Lysine (K)-specific demethylase 4B \\
\hline 5366 & 204286_s_at & PMAIP1 & Phorbol-12-myristate-13-acetate-induced protein 1 \\
\hline 11098 & 202458_at & PRSS23 & Protease, serine, 23 \\
\hline 5744 & 211756_at & PTHLH & Parathyroid hormone-like hormone \\
\hline 157869 & 214725_at & SBSPON & Somatomedin B and thrombospondin, type 1 domain containing \\
\hline
\end{tabular}


Table 4 Genes downregulated within parous breast (Continued)

\begin{tabular}{llll}
\hline EntrezID & ProbelD & Symbol & GeneName \\
\hline 1811 & 206143_at & SLC26A3 & Solute carrier family 26, member 3 \\
51012 & 229835_s_at & SLMO2 & Slowmo homolog 2 (Drosophila) \\
6431 & 206108_s_at & SRSF6 & Serine/arginine-rich splicing factor 6 \\
27324 & 216623_x_at & TOX3 & TOX high mobility group box family member 3 \\
7366 & 207392_x_at & UGT2B15 & UDP glucuronosyltransferase 2 family, polypeptide B15 \\
151126 & 1555801_s_at & ZNF385B & Zinc finger protein 385B \\
\hline
\end{tabular}

breast. This data suggest that there are differences in the number of activated $\mathrm{T}$ cells between $\mathrm{P}$ and $\mathrm{NP}$ breast (Fig. 7).

Normal pregnancy is characterized by an early expansion of regulatory $\mathrm{T}$ cells [64], which modulate immune tolerance during pregnancy [64]. In addition, microchimeric cells of fetal origin that persist in the maternal circulation after delivery are postulated to provide immune surveillance with the contribution of $\mathrm{T}$ cells, protecting against breast cancer [65-67]. Evidence shows that microchimeric cells are more frequent in healthy women than in breast cancer-affected women, and breast cancers without circulating microchimeric cells are more aggressive [65-70]. In this work, we found several upregulated genes related to activation of T cells after FTP (Additional files 2, 3 , and 4). This suggests that the activation of T cells in the breast tissue of $\mathrm{P}$ women could trigger an early response against transformed cells, destroying them and protecting the mammary gland from neoplastic transformation. Tumor surveillance by the immune system and its impact on disease outcomes in cancer patients, and in breast cancer patients in particular, have been documented [71-75]. Finak et al. studied the stromal gene expression and clinical outcomes in breast cancer and observed that the gene set expressed predominantly in the good-outcome cluster was enriched by elements of the $\mathrm{T}$ helper type 1 [71]. Eight (CD2, CD8A, XCL1, CD3D, GZMA, CD247, CD48, CD52) of the genes present in this cluster [71] were also upregulated in the parous women. Poor-outcome cluster [71] showed downregulation of CXCL14, which was upregulated in the parous breast, and upregulation of CXCL1 and EDN1, which were downregulated in the parous breast. This overlap between Finak study and ours indicates that the activation of the $\mathrm{T}$ cell response is a beneficial mechanism against transformed cells. Winslow et al. described gene sets with better prognostics for triple-negative breast cancers [72]. These gene sets involved cytotoxic immune response, including the genes mentioned above, and HLA encoding genes [72]. HLA-DRA (major histocompatibility complex, class II, DR alpha) and HLA-DPA1 (major histocompatibility complex, class II, DP alpha 1) were constantly activated in our study. The upregulation of HLA-DPA1 has been associated with a benign behavior of certain neurological tumors and related to the immune defense-associated genes [76]. Therefore, a similar role could be attributed to the upregulation of these two genes in the cancer preventative effect of pregnancy in the premenopausal women.

Using tissue from nine women whom arrays could be conducted in epithelial tissue, stromal tissue, and whole

Table 5 Correlation of real-time RT-PCR and microarray results

\begin{tabular}{|c|c|c|c|c|c|c|c|c|}
\hline \multirow[t]{2}{*}{ Genes } & \multirow{2}{*}{$\begin{array}{l}\text { Affymetrix } \\
\text { probeset }\end{array}$} & \multirow[t]{2}{*}{ TaqMan Assay ID } & \multicolumn{2}{|c|}{ Microarray } & \multicolumn{2}{|c|}{ Real time } & \multirow[t]{2}{*}{ ICC } & \multirow{2}{*}{$\begin{array}{l}\text { Spearman } \\
\text { correlation }\end{array}$} \\
\hline & & & FC & $P$ & $\overline{F C}$ & $P$ & & \\
\hline WIF1 & 204712_at & Hs00183662_m1 & 0.39 & 0.055 & 0.32 & 0.034 & 0.92 & 0.94 \\
\hline FOXQ1 & 227475_at & Hs00536425_s1 & 0.64 & 0.020 & 0.70 & 0.218 & 0.64 & 0.69 \\
\hline FZD8 & 227405_s_at & Hs00259040_s1 & 1.3 & 0.003 & 1.17 & 0.188 & 0.43 & 0.42 \\
\hline SDC1 & 201286_at & Hs00896423_m1 & 1.48 & 0.014 & 1.19 & 0.456 & 0.73 & 0.62 \\
\hline EAF2 & 219551_at & Hs00218407_m1 & 1.36 & 0.008 & 1.24 & 0.059 & 0.35 & 0.41 \\
\hline BHLHE22 & 228636_at & Hs01084964_s1 & 1.24 & 0.078 & 1.35 & 0.022 & 0.41 & 0.53 \\
\hline APOBEC3G & 204205_at & Hs00222415_m1 & 1.44 & 0.000 & 1.44 & 0.001 & 0.39 & 0.48 \\
\hline DSC3 & 206033_s_at & Hs00170032_m1 & 1.70 & 0.002 & 1.45 & 0.063 & 0.64 & 0.51 \\
\hline KRT5 & 201820_at & Hs00361185_m1 & 1.51 & 0.012 & 1.54 & 0.062 & 0.64 & 0.71 \\
\hline EGR3 & 206115_at & Hs00231780_m1 & 1.71 & 0.026 & 1.57 & 0.072 & 0.76 & 0.70 \\
\hline RASGRP1 & 205590_at & Hs00996727_m1 & 1.61 & 0.002 & 1.71 & 0.002 & 0.66 & 0.74 \\
\hline
\end{tabular}

Correlation of real-time RT-PCR and microarray results were calculated using the 20 parous vs. 17 nulliparous samples, for whom enough RNA material was still available. FC mean fold change, $P$ batch-adjusted $p$ value, ICC intraclass correlation coefficient 
Table 6 Gene alteration in 5796 breast cancer subjects

\begin{tabular}{lll}
\hline Genes & Number of samples altered & Percent of samples altered \\
\hline BHLHE22 & 400 & 6.9 \\
EGR3 & 87 & 1.5 \\
WIF1 & 73 & 1.3 \\
FOXQ1 & 73 & 1.3 \\
FZD8 & 64 & 1.1 \\
DSC3 & 57 & 1.0 \\
KRT5 & 55 & 1.0 \\
SDC1 & 35 & 0.6 \\
EAF2 & 30 & 0.5 \\
RASGRP1 & 30 & 0.5 \\
APOBEC3G & 28 & 0.5 \\
\hline
\end{tabular}

tissue, we observed that a linear regression of gene expression in epithelial and stromal tissues predicted gene expression in the whole tissue extremely well $\left(R^{2} \geq 0.90\right.$ for all subjects). We also observed that the proportion of each tissue in the whole-tissue biopsy sample (as estimated by the linear regression coefficient) varied substantially across women (range for epithelial tissue, 0.09-0.68) (Table 7). This suggests that the P/NP gene expression differences we observed either are present in each of the two tissues (epithelial and stromal) or are present in only one of the two tissues but are of such magnitude that they are observed in whole tissue biopsies, despite the fact that some of the individual biopsies may contain only a small proportion of this tissue type.

When comparing gene expression in stroma versus epithelia, we observed a large number of genes differentially expressed among these two tissues. The epithelia, being a more differentiated tissue, enriched fewer GO terms, and these were mainly involved in epithelial development and tight junction (Additional file 7). The stroma showed enrichment of a broader range of functions, lipid homeostasis, lipid storage, metabolic process, vascularization, and migration to cite a few (Additional file 7). This extensive list of biological process is expected because the stroma is constituted of different types of cells (e.g., adipocytes, fibroblasts, endothelial cells). Among the genes found in the stroma, we did not observe enrichment of many immune-related GO terms, which is consistent with the fact we did not observe a large number of immune cells in the histopathology of these samples. Furthermore, parity status was not included in the comparison of the epithelia vs. stroma. Among the samples used in the LCM analyses (5 NP and $5 \mathrm{P}$ ), only one had the FTP less than 5 years

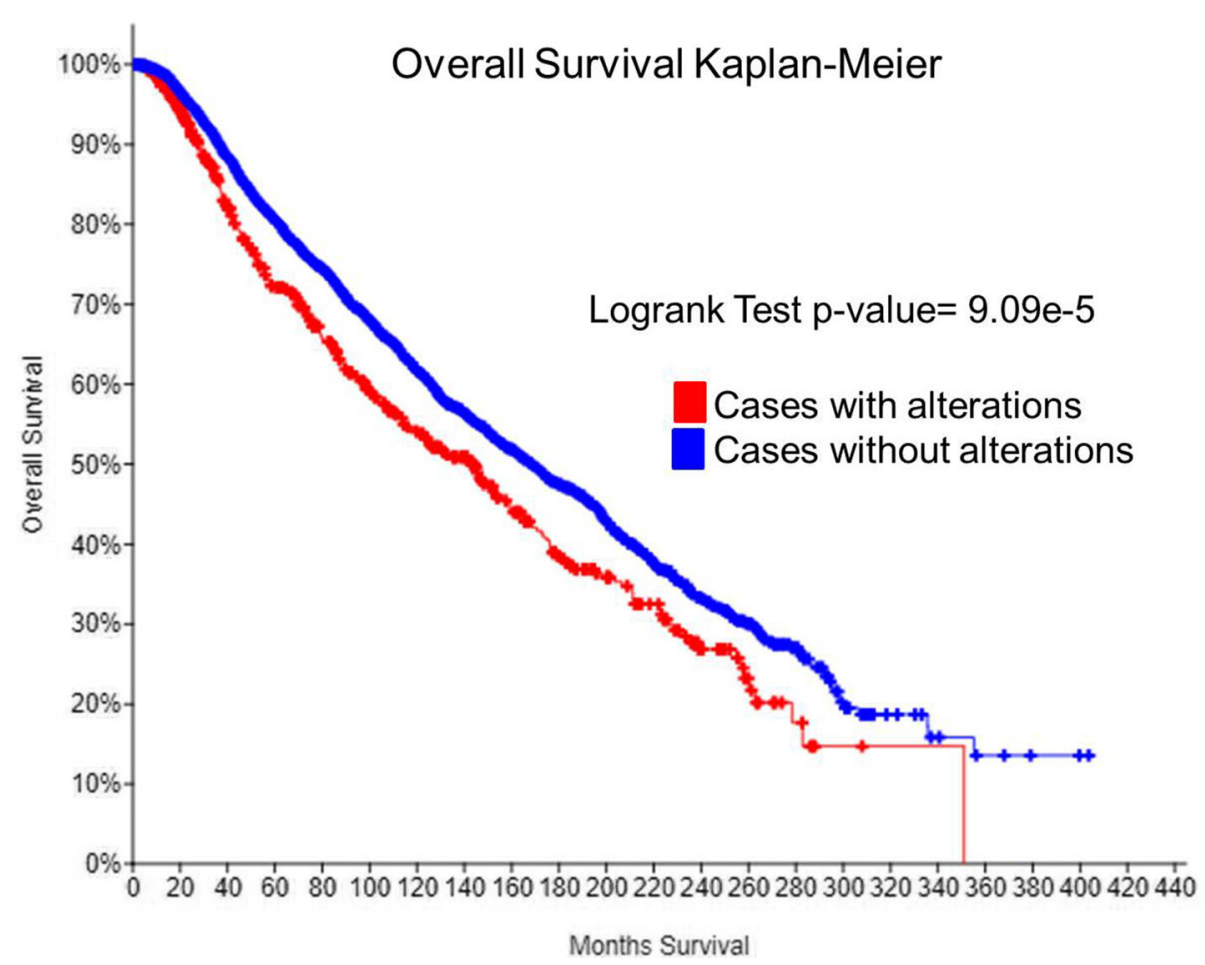

Fig. 6 Analyses of the parous differentially expressed genes in breast cancer patients. Genes that were selected for real-time RT-PCR validation were also used for evaluation into breast cancer patients using the cBioPortal tool (http://www.cbioportal.org/), overall Kaplan-Meier survival curve comparing between the cases with and without alterations in these genes. Patients that contained alterations had a median of 143.13 months overall survival while patients without alteration in these genes had median of 168.3 (logrank test $p$ value $=9.09 \mathrm{e}-5$ ) 

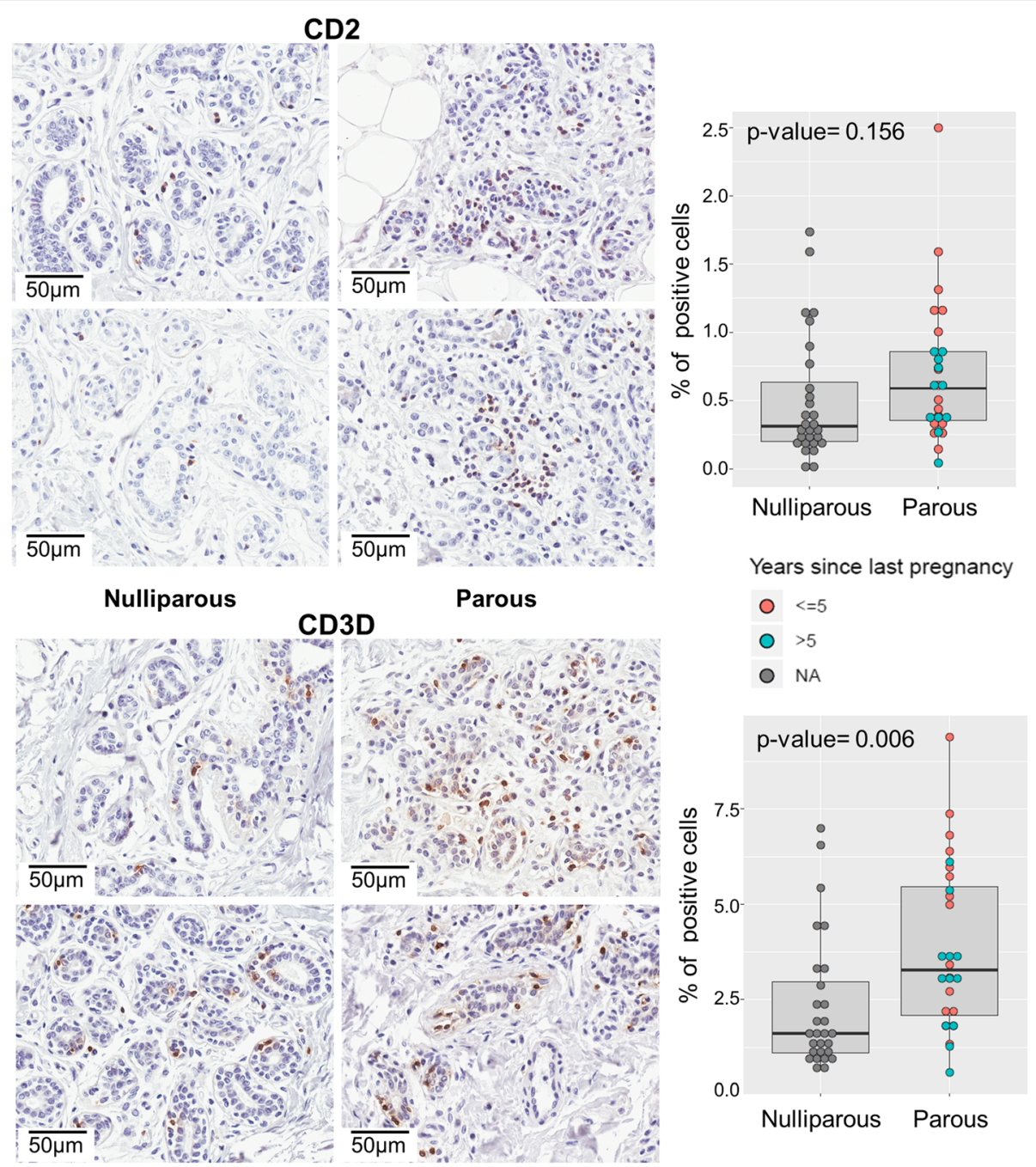

Fig. 7 Immunohistochemical evaluation of CD2 and CD3D for T cell activation. On the top are results regarding CD2, and on the bottom are results of CD3D. Panels on the left show the imunohistochemical reactions $(\times 400)$, each panel contains two nulliparous samples (left) and two parous samples (right). On the right, boxplots show the percentage of positive cells. We observe an increase in the percentage of CD3D-positive cells in the parous group ( $p$ value $=0.006)$

Table 7 Linear regression coefficients of gene expression levels in breast tissue

\begin{tabular}{llll}
\hline Subject & \multicolumn{2}{l}{$\beta$ coefficients } & $R^{2}$ \\
\cline { 2 - 3 } & Epithelial tissue & Stromal tissue & \\
\hline 1 & 0.091 & 0.910 & 0.943 \\
2 & 0.461 & 0.503 & 0.945 \\
3 & 0.495 & 0.425 & 0.905 \\
4 & 0.516 & 0.406 & 0.922 \\
5 & 0.287 & 0.624 & 0.929 \\
6 & 0.354 & 0.622 & 0.953 \\
7 & 0.681 & 0.308 & 0.920 \\
8 & 0.342 & 0.654 & 0.939 \\
9 & 0.122 & 0.877 & 0.926 \\
\hline
\end{tabular}

before the biopsy, the group in which we found significant enrichment of immune response genes in the P/NP main study. The limited number of successful LCM microarrays did not allow us to perform analyses to understand whether parity induced more changes in expression of genes present in the stromal or epithelial cells of the breast.

This study has several strengths. A major strength is that all women were volunteers from the general population who were free of any breast abnormality. Also, all biopsies were histologically examined to confirm normality of tissue and presence of breast epithelium and stroma. Histological evaluations and gene expression experiments were performed on unidentifiable samples to prevent bias. Our study also had limitations. Because our main analysis was based on whole breast tissue 
microarrays, we were not able to characterize parity-associated differences in gene expression separately for epithelial and stromal tissues. While this would be of interest, it would require large biopsies in order to obtain a sufficient amount of each tissue type, which is difficult to justify in studies of healthy volunteers. The variability in composition of breast tissue among women adds to the challenge of understanding the mechanisms responsible for the preventive effect of parity and comparison of different studies. Because of the limited sample size, we could not conduct our analysis by time since last pregnancy partitioning our data in discovery/validation. Lastly, these results were generated based on a relatively homogenous population; therefore, confirmation of these results including a more ethnically heterogeneous population is needed.

\section{Conclusions}

Altogether, parous premenopausal breast shows a specific transcriptome profile, in which genes controlling chromatin remodeling and cell differentiation are activated after FTP and stay upregulated for many years, supporting the data from postmenopausal parous women previously published [6-8].

Of great novelty is that this work shows that the genes involved in immune response were in majority related to $T$ cell activation and these were activated soon after the FTP; however, their expression return to levels similar to those observed in the nulliparous breast five or more years after FTP. These transcripts may work in protecting the mammary gland against neoplastically transformed cells through $T$ cells. However, because this immune surveillance appears transitory, we infer that cell differentiation, activated by the genes whose expression was permanently affected by parity, may be the main molecular mechanism responsible for the preventive effect of parity against breast cancer.

\section{Additional files}

Additional file 1: Complete list of differentially expressed probesets (416 probes). (XLSX $101 \mathrm{~kb}$ )

Additional file 2: Complete list of $\mathrm{GO}$ terms enriched by the transient genes. (XLSX $23 \mathrm{~kb}$ )

Additional file 3: Complete list of $\mathrm{GO}$ terms enriched by the long-term changing genes. (XLSX $16 \mathrm{~kb}$ )

Additional file 4: Complete list of $\mathrm{GO}$ terms enriched by the long-term constant genes. (XLSX $20 \mathrm{~kb}$ )

Additional file 5: Real-time RT-PCR raw data. (XLSX $17 \mathrm{~kb}$ )

Additional file 6: Genes differentially expressed between epithelial and stromal tissues. (XLSX $189 \mathrm{~kb})$

Additional file 7: Complete list of GO terms enriched by the genes differentially expressed in epithelial and stromal tissues. (XLSX $61 \mathrm{~kb}$ )

\section{Abbreviations}

BMI: Body mass index; CV: Coefficient of variation; FDR: False discovery rate; FTP: Full-term pregnancy; GO: Gene Ontology; IPA: Ingenuity ${ }^{\oplus}$ Pathways Analysis; LCM: Laser capture microdissection; NP: Nulliparous;
NUSE: Normalized Unscaled Standard Error; P: Parous; PLM: Probe-level models; QC: Quality control; RMA: Robust Multi-Array Average; RT-PCR: Reverse transcription polymerase chain reaction; TSLP: Time since last pregnancy; WT: Whole tissue

\section{Acknowledgements}

The authors thank the women of Norrbotten County, Sweden, for their willing contribution to the project, the staff of the Mammography Department, Sunderby Hospital, Luleå, Sweden, and Fox Chase Cancer Center Genomics Facility.

\section{Funding}

This work was supported by grant 02-2010-117 from the Avon Foundation for Women Breast Cancer Research Program and by NCI P30-CA006927 to Fox Chase Cancer Center.

\section{Availability of data and materials}

The datasets generated and analyzed during the current study are available in the Gene Expression Omnibus (GEO) repository. The data regarding the analysis of P vs. NP has accession number GSE1 12825 [https://www.ncbi.nlm. nih.gov/geo/query/acc.cgi?acc=GSE112825]. The data generated from the LCM substudy has accession number GSE111662 [https://www.ncbi.n/m.nih. gov/geo/query/acc.cgi?acc=GSE111662].

\section{Authors' contributions}

JSP performed the gene expression experiments, analyses, interpretation of data and wrote the manuscript. AZJ performed the analysis of data and wrote the manuscript. YA performed the analysis of data and wrote the manuscript. $\mathrm{HZ}$ performed the analysis of data and wrote the manuscript. MS performed the analysis of data. SP performed the analysis of the data. EAR performed the analysis and interpretation of the data. RLC performed the gene expression experiments. YZ performed the gene expression experiments. TN performed the laser microdissections and RNA isolation. FS performed the laser microdissections. IHR designed the project. YS performed the immunohistochemistry. AAA performed the interpretation of the data and wrote the manuscript. PB planned, organized, and led the field work, evaluated the breast status, and performed the breast biopsies.

PL worked with the ethical committee and organized the field work. JA planned, organized, and executed the field work, was the contact person for the volunteers, administered the study questionnaires, conducted the inclusion/exclusion process, performed the exams, assisted with the needle biopsies, and delivered the data and specimen to Umea University. ASL planned, organized, and executed field work, evaluated the breast status, and performed the breast biopsies. RJ performed the field work. GH designed the project. PT designed the project and coordinated with the research groups. $J R$ designed the project, performed the interpretation of the data, and wrote the manuscript. All authors read and approved the final manuscript.

\section{Ethics approval and consent to participate}

This study was reviewed and approved by the Regional Ethical Review Board for Northern Sweden at the University of Umeå, Sweden (Dnr07-156 M with amendments 08-020 and 2010/397-32) and by Internal Review Board of Fox Chase Cancer Center, USA (FCCC-IRB 02-829). All volunteers that were involved in this work signed informed consent to participate in this study.

\section{Consent for publication}

Not applicable

\section{Competing interests}

The authors declare that they have no competing interests.

\section{Publisher's Note}

Springer Nature remains neutral with regard to jurisdictional claims in published maps and institutional affiliations.

\section{Author details}

'The Irma H. Russo, MD Breast Cancer Research Laboratory, Fox Chase Cancer Center - Temple University Health System, 333 Cottman Ave, P2051, Philadelphia, PA 19111, USA. ${ }^{2}$ Division of Epidemiology, Department of Population Health, New York University School of Medicine, New York, NY 10016, USA. ${ }^{3}$ New York University Perlmutter Cancer Center, New York, NY 
10016, USA. ${ }^{4}$ Department of Biostatistics and Bioinformatics, Fox Chase Cancer Center - Temple University Health System, Philadelphia, PA 19111, USA. ${ }^{5}$ Department of Obstetrics and Gynecology, New York University School of Medicine, New York, NY 10016, USA. ${ }^{6}$ Sunderby Hospital, Luleå and the Norrbotten Mammography Screening Program, Luleå, Sweden. 'Departments of Radiation Sciences and Oncology, Umeå University, Umeå, Sweden. ${ }^{8}$ Department of Biobank Research, Umeå University, Umeå, Sweden. ${ }^{9}$ Department of Public Health and Clinical Medicine, Umeå University, Umeå, Sweden.

Received: 16 March 2018 Accepted: 14 March 2019 Published online: 28 March 2019

\section{References}

1. Russo J, Moral R, Balogh GA, Mailo D, Russo $\mathrm{H}$. The protective role of pregnancy in breast cancer. Breast Cancer Res. 2005;7:131-42

2. Cancer CGoHFiB. Breast cancer and breastfeeding: collaborative reanalysis of individual data from 47 epidemiological studies in 30 countries, including 50302 women with breast cancer and 96973 women without the disease Lancet. 2002:360:187-95.

3. Russo J, Tay LK, Russo $\mathbb{H}$. Differentiation of the mammary gland and susceptibility to carcinogenesis. Breast Cancer Res Treat. 1982;2:5-73.

4. Russo $\mathrm{H}$, Koszalka M, Russo J. Comparative study of the influence of pregnancy and hormonal treatment on mammary carcinogenesis. $\mathrm{Br} J$ Cancer. 1991;64:481-4.

5. Albrektsen G, Heuch I, Hansen S, Kvale G. Breast cancer risk by age at birth, time since birth and time intervals between births: exploring interaction effects. Br J Cancer. 2005:92:167-75.

6. Belitskaya-Levy I, Zeleniuch-Jacquotte A, Russo J, Russo IH, Bordas P, Ahman $J$, et al. Characterization of a genomic signature of pregnancy identified in the breast. Cancer Prev Res (Phila). 2011:4:1457-64

7. Peri S, de Cicco RL, Santucci-Pereira J, Slifker M, Ross EA, Russo $H_{\text {, et al. Defining }}$ the genomic signature of the parous breast. BMC Med Genet. 2012;5:46.

8. Russo J, Santucci-Pereira J, de Cicco RL, Sheriff F, Russo PA, Peri S, et al. Pregnancy-induced chromatin remodeling in the breast of postmenopausal women. Int J Cancer. 2012;131:1059-70.

9. Bolstad BM, Collin F, Brettschneider J, Simpson K, Cope L, Irizarry RA, et al. Quality assessment of Affymetrix GeneChip Data. In: Gentleman R, Carey V Huber W, Irizarry R, Dudoit S, editors. Bioinformatics and computational biology solutions using R and bioconductor. New York: Springer; 2005. p. 33-47.

10. R: a language and environment for statistical computing. http://www.Rproject.org.

11. Gentleman RC, Carey VJ, Bates DM, Bolstad B, Dettling M, Dudoit S, et al. Bioconductor: open software development for computational biology and bioinformatics. Genome Biol. 2004;5:R80

12. Johnson WE, Li C, Rabinovic A. Adjusting batch effects in microarray expression data using empirical Bayes methods. Biostatistics. 2007;8:118-27.

13. Leek JT, Johnson WE, Parker HS, Jaffe AE, Storey JD. The sva package for removing batch effects and other unwanted variation in high-throughput experiments. Bioinformatics. 2012;28:882-3.

14. Storey JD, Tibshirani R. Statistical significance for genomewide studies. Proc Natl Acad Sci U S A. 2003;100:9440-5.

15. Saeed Al, Sharov V, White J, Li J, Liang W, Bhagabati N, et al. TM4: a free, open-source system for microarray data management and analysis. Biotechniques. 2003:34:374-8.

16. Falcon S, Gentleman R. Using GOstats to test gene lists for GO term association. Bioinformatics. 2007;23:257-8.

17. Ashburner M, Ball CA, Blake JA, Botstein D, Butler H, Cherry JM, et al. Gene ontology: tool for the unification of biology. The Gene Ontology Consortium. Nat Genet. 2000;25:25-9.

18. Gao J, Aksoy BA, Dogrusoz U, Dresdner G, Gross B, Sumer SO, et al. Integrative analysis of complex cancer genomics and clinical profiles using the cBioPortal. Sci Signal. 2013;6:pl1.

19. Cerami E, Gao J, Dogrusoz U, Gross BE, Sumer SO, Aksoy BA, et al. The cBio cancer genomics portal: an open platform for exploring multidimensional cancer genomics data. Cancer Discov. 2012;2:401-4.

20. Coudry RA, Meireles SI, Stoyanova R, Cooper HS, Carpino A, Wang X, et al. Successful application of microarray technology to microdissected formalinfixed, paraffin-embedded tissue. J Mol Diagn. 2007;9:70-9.

21. North AJ, Chidgey MA, Clarke JP, Bardsley WG, Garrod DR. Distinct desmocollin isoforms occur in the same desmosomes and show reciprocally graded distributions in bovine nasal epidermis. Proc Natl Acad Sci U S A. 1996:93:7701-5.

22. KRT5 keratin 5. Homo sapiens (human). http://www.ncbi.nlm.nih.gov/gene/3852. Accessed Feb 2018.

23. Cui T, Chen Y, Yang L, Knosel T, Huber O, Pacyna-Gengelbach M, et al. The p53 target gene desmocollin 3 acts as a novel tumor suppressor through inhibiting EGFR/ERK pathway in human lung cancer. Carcinogenesis. 2012; 33:2326-33.

24. Chen J, O'Shea C, Fitzpatrick JE, Koster MI, Koch PJ. Loss of Desmocollin 3 in skin tumor development and progression. Mol Carcinog. 2012;51: 535-45.

25. Knosel T, Chen $Y$, Hotovy S, Settmacher U, Altendorf-Hofmann A, Petersen I. Loss of desmocollin 1-3 and homeobox genes PITX1 and CDX2 are associated with tumor progression and survival in colorectal carcinoma. Int J Color Dis. 2012;27:1391-9.

26. Oshiro MM, Kim CJ, Wozniak RJ, Junk DJ, Munoz-Rodriguez JL, Burr JA, et al. Epigenetic silencing of DSC3 is a common event in human breast cancer. Breast Cancer Res. 2005;7:R669-80.

27. Vasiliu D, Clamons S, McDonough M, Rabe B, Saha M. A regression-based differential expression detection algorithm for microarray studies with ultralow sample size. PLoS One. 2015:10:e0118198.

28. Braga-Neto UM, Dougherty ER. Is cross-validation valid for small-sample microarray classification? Bioinformatics. 2004;20:374-80.

29. Huang $H$, Jin T, Wang L, Wang F, Zhang R, Pan $Y$, et al. The RAS guanyl nucleotide-releasing protein RasGRP1 is involved in lymphatic development in zebrafish. J Biol Chem. 2013;288:2355-64.

30. Kortum RL, Rouquette-Jazdanian AK, Samelson LE. Ras and extracellular signal-regulated kinase signaling in thymocytes and T cells. Trends Immunol. 2013;34:259-68.

31. To SQ, Knower KC, Clyne CD. NFkappaB and MAPK signalling pathways mediate TNFalpha-induced early growth response gene transcription leading to aromatase expression. Biochem Biophys Res Commun. 2013:433: 96-101.

32. Dugas JC, Ibrahim A, Barres BA. The T3-induced gene KLF9 regulates oligodendrocyte differentiation and myelin regeneration. Mol Cell Neurosci. 2012;50:45-57.

33. Wang $\mathrm{HQ}$, Xu ML, Ma J, Zhang Y, Xie CH. Frizzled-8 as a putative therapeutic target in human lung cancer. Biochem Biophys Res Commun. 2012:417:62-6

34. Katoh M. WNT signaling in stem cell biology and regenerative medicine. Curr Drug Targets. 2008;9:565-70.

35. Meier-Abt F, Milani E, Roloff T, Brinkhaus H, Duss S, Meyer DS, et al. Parity induces differentiation and reduces Wnt/Notch signaling ratio and proliferation potential of basal stem/progenitor cells isolated from mouse mammary epithelium. Breast Cancer Res. 2013;15:R36.

36. Russo J, Santucci-Pereira J, Russo $1 \mathrm{H}$. The genomic signature of breast cancer prevention. Genes. 2014;5:65-83.

37. Wan X, Ji W, Mei X, Zhou J, Liu JX, Fang C, et al. Negative feedback regulation of Wnt4 signaling by EAF1 and EAF2/U19. PLoS One. 2010;5:e9118.

38. Su F, Pascal LE, Xiao W, Wang Z. Tumor suppressor U19/EAF2 regulates thrombospondin-1 expression via p53. Oncogene. 2010;29:421-31.

39. Wissmann C, Wild PJ, Kaiser S, Roepcke S, Stoehr R, Woenckhaus M, et al. WIF1, a component of the Wnt pathway, is down-regulated in prostate, breast, lung, and bladder cancer. J Pathol. 2003;201:204-12.

40. Ai L, Tao Q, Zhong S, Fields CR, Kim WJ, Lee MW, et al. Inactivation of Wnt inhibitory factor-1 (WIF1) expression by epigenetic silencing is a common event in breast cancer. Carcinogenesis. 2006;27:1341-8.

41. Russo J, Balogh GA, Chen J, Fernandez SV, Fernbaugh R, Heulings R, et al. The concept of stem cell in the mammary gland and its implication in morphogenesis, cancer and prevention. Front Biosci. 2006;11:151-72.

42. Christensen J, Bentz S, Sengstag T, Shastri VP, Anderle P. FOXQ1, a novel target of the Wnt pathway and a new marker for activation of Wnt signaling in solid tumors. PLoS One. 2013;8:e60051.

43. Sehrawat A, Kim SH, Vogt A, Singh SV. Suppression of FOXQ1 in benzyl isothiocyanate-mediated inhibition of epithelial-mesenchymal transition in human breast cancer cells. Carcinogenesis. 2013;34:864-73.

44. Qiao Y, Jiang X, Lee ST, Karuturi RK, Hooi SC, Yu Q. FOXQ1 regulates epithelial-mesenchymal transition in human cancers. Cancer Res. 2011;71: 3076-86.

45. Gao M, Shih le M, Wang TL. The role of forkhead box Q1 transcription factor in ovarian epithelial carcinomas. Int J Mol Sci. 2012;13:13881-93. 
46. Tessema M, Yingling CM, Grimes MJ, Thomas CL, Liu Y, Leng S, et al. Differential epigenetic regulation of TOX subfamily high mobility group box genes in lung and breast cancers. PLoS One. 2012;7:e34850.

47. Aliahmad P, de la Torre B, Kaye J. Shared dependence on the DNA-binding factor TOX for the development of lymphoid tissue-inducer cell and NK cell lineages. Nat Immunol. 2010;11:945-52.

48. Aliahmad P, Kadavallore A, de la Torre B, Kappes D, Kaye J. TOX is required for development of the CD4 T cell lineage gene program. J Immunol. 2011; 187:5931-40.

49. Unoki M, Nishidate T, Nakamura Y. ICBP90, an E2F-1 target, recruits HDAC1 and binds to methyl-CpG through its SRA domain. Oncogene. 2004;23:7601-10.

50. Jin W, Chen L, Chen Y, Xu SG, Di GH, Yin WJ, et al. UHRF1 is associated with epigenetic silencing of BRCA1 in sporadic breast cancer. Breast Cancer Res Treat. 2010;123:359-73.

51. Attia M, Forster A, Rachez C, Freemont $\mathrm{P}$, Avner $\mathrm{P}$, Rogner UC. Interaction between nucleosome assembly protein 1-like family members. J Mol Biol. 2011;407:647-60.

52. Attia M, Rachez C, De Pauw A, Avner P, Rogner UC. Nap1/2 promotes histone acetylation activity during neuronal differentiation. Mol Cell Biol. 2007;27:6093-102.

53. Lackey L, Law EK, Brown WL, Harris RS. Subcellular localization of the APOBEC3 proteins during mitosis and implications for genomic DNA deamination. Cell Cycle. 2013;12:762-72.

54. Long J, Delahanty RJ, Li G, Gao YT, Lu W, Cai Q, et al. A common deletion in the APOBEC3 genes and breast cancer risk. J Natl Cancer Inst. 2013;105:573-9.

55. Monks J, Geske FJ, Lehman L, Fadok VA. Do inflammatory cells participate in mammary gland involution? J Mammary Gland Biol Neoplasia. 2002;7:163-76.

56. Csanaky K, Doppler W, Tamas A, Kovacs K, Toth G, Reglodi D. Influence of terminal differentiation and PACAP on the cytokine, chemokine, and growth factor secretion of mammary epithelial cells. J Mol Neurosci. 2014;52:28-36.

57. Martinson HA, Jindal S, Durand-Rougely C, Borges VF, Schedin P. Wound healing-like immune program facilitates postpartum mammary gland involution and tumor progression. Int J Cancer. 2015;136:1803-13.

58. Plaks V, Boldajipour B, Linnemann JR, Nguyen NH, Kersten K, Wolf $Y$, et al. Adaptive immune regulation of mammary postnatal organogenesis. Dev Cell. 2015;34:493-504.

59. Asztalos S, Gann PH, Hayes MK, Nonn L, Beam CA, Dai Y, et al. Gene expression patterns in the human breast after pregnancy. Cancer Prev Res (Phila). 2010;3:301-11.

60. Rotunno M, Sun X, Figueroa J, Sherman ME, Garcia-Closas M, Meltzer P, et al. Parity-related molecular signatures and breast cancer subtypes by estrogen receptor status. Breast Cancer Res. 2014;16:R74.

61. Clarkson RW, Wayland MT, Lee J, Freeman T, Watson CJ. Gene expression profiling of mammary gland development reveals putative roles for death receptors and immune mediators in post-lactational regression. Breast Cancer Res. 2004;6:R92-109.

62. Stein T, Morris JS, Davies CR, Weber-Hall SJ, Duffy MA, Heath VJ, et al. Involution of the mouse mammary gland is associated with an immune cascade and an acute-phase response, involving LBP, CD14 and STAT3. Breast Cancer Res. 2004;6:R75-91.

63. Liu Q, Wuu J, Lambe M, Hsieh SF, Ekbom A, Hsieh CC. Transient increase in breast cancer risk after giving birth: postpartum period with the highest risk (Sweden). Cancer Causes Control. 2002;13:299-305.

64. Schumacher A, Heinze K, Witte J, Poloski E, Linzke N, Woidacki K, et al. Human chorionic gonadotropin as a central regulator of pregnancy immune tolerance. J Immunol. 2013;190:2650-8.

65. Gadi VK. Fetal microchimerism in breast from women with and without breast cancer. Breast Cancer Res Treat. 2010;121:241-4.

66. Gadi VK. Fetal microchimerism and cancer. Cancer Lett. 2009;276:8-13.

67. Gadi VK, Nelson JL. Fetal microchimerism in women with breast cancer. Cancer Res. 2007;67:9035-8.

68. Eun JK, Guthrie KA, Zirpoli G, Gadi VK. In situ breast cancer and microchimerism. Sci Rep. 2013;3:2192.

69. Boyon C, Collinet P, Boulanger L, Rubod C, Lucot JP, Vinatier D. Fetal microchimerism: benevolence or malevolence for the mother? Eur J Obstet Gynecol Reprod Biol. 2011;158:148-52.

70. Kallenbach $\mathrm{LR}$, Johnson $\mathrm{KL}$, Bianchi DW. Fetal cell microchimerism and cancer: a nexus of reproduction, immunology, and tumor biology. Cancer Res. 2011;71:8-12.
71. Finak G, Bertos N, Pepin F, Sadekova S, Souleimanova M, Zhao H, et al. Stromal gene expression predicts clinical outcome in breast cancer. Nat Med. 2008;14:518-27.

72. Winslow S, Leandersson K, Edsjo A, Larsson C. Prognostic stromal gene signatures in breast cancer. Breast Cancer Res. 2015;17:23.

73. Nagalla S, Chou JW, Willingham MC, Ruiz J, Vaughn JP, Dubey P, et al. Interactions between immunity, proliferation and molecular subtype in breast cancer prognosis. Genome Biol. 2013;14:R34.

74. Farmer $\mathrm{P}$, Bonnefoi $\mathrm{H}$, Anderle $\mathrm{P}$, Cameron D, Wirapati $\mathrm{P}$, Becette $\mathrm{V}$, et al. A stroma-related gene signature predicts resistance to neoadjuvant chemotherapy in breast cancer. Nat Med. 2009;15:68-74.

75. Mahmoud SM, Paish EC, Powe DG, Macmillan RD, Grainge MJ, Lee AH, et al. Tumor-infiltrating CD8+ lymphocytes predict clinical outcome in breast cancer. J Clin Oncol. 2011;29:1949-55.

76. Huang H, Hara A, Homma T, Yonekawa Y, Ohgaki H. Altered expression of immune defense genes in pilocytic astrocytomas. J Neuropathol Exp Neurol. 2005;64:891-901.

\section{Ready to submit your research? Choose BMC and benefit from:}

- fast, convenient online submission

- thorough peer review by experienced researchers in your field

- rapid publication on acceptance

- support for research data, including large and complex data types

- gold Open Access which fosters wider collaboration and increased citations

- maximum visibility for your research: over $100 \mathrm{M}$ website views per year

At BMC, research is always in progress.

Learn more biomedcentral.com/submissions 